\title{
Signaling Pathways That Regulate the Enhanced Disease Resistance of Arabidopsis “Defense, No Death" Mutants
}

\author{
Ruth K. Genger, ${ }^{1}$ Grace I. Jurkowski, ${ }^{1}$ John M. McDowell, ${ }^{2}$ Hua Lu, ${ }^{3}$ Ho Won Jung, ${ }^{3}$ Jean T. Greenberg, ${ }^{3}$ \\ and Andrew F. Bent ${ }^{1}$
${ }^{1}$ Department of Plant Pathology, University of Wisconsin-Madison, Madison, WI 53706, U.S.A.; ${ }^{2}$ Department of Plant Pathology, Physiology and Weed Science, Virginia Tech, Blacksburg, VA 24061, U.S.A.; ${ }^{3}$ Department of Molecular Genetics and Cell Biology, University of Chicago, Chicago, IL 60637, U.S.A.

Submitted 11 February 2008. Accepted 22 May 2008.

\begin{abstract}
Arabidopsis $d n d 1$ and $d n d 2$ mutants lack cyclic nucleotidegated ion channel proteins and carry out avirulence or resistance gene-mediated defense with a greatly reduced hypersensitive response (HR). They also exhibit elevated broad-spectrum disease resistance and constitutively elevated salicylic acid (SA) levels. We examined the contributions of NPR1, SID2 (EDS16), NDR1, and EIN2 to dnd phenotypes. Mutations that affect SA accumulation or signaling (sid2, npr1, and ndr1) abolished the enhanced resistance of $d$ d mutants against Pseudomonas syringae pv. tomato and Hyaloperonospora parasitica but not Botrytis cinerea. When SA-associated pathways were disrupted, the constitutive activation of NPRI-dependent and NPRI-independent and $\mathrm{SA}$-dependent pathways was redirected toward PDF1.2-associated pathways. This PDF1.2 overexpression was downregulated after infection by $P$. syringae. Disruption of ethylene signaling abolished the enhanced resistance to $B$. cinerea but not $P$. syringae or $H$. parasitica. However, loss of NPR1, SID2, NDR1, or EIN2 did not detectably alter the reduced HR in $d n d$ mutants. The susceptibility of $d n d$ ein 2 plants to $B$. cinerea despite their reducedHR phenotype suggests that cell death repression is not the primary cause of $\boldsymbol{d n d}$ resistance to necrotrophic pathogens. The partial restoration of resistance to $B$. cinerea in $\mathrm{dnd} 1$ npr1 ein2 triple mutants indicated that this resistance is not entirely EIN2 dependent. The above findings indicate that the broad-spectrum resistance of $d n d$ mutants occurs due to activation or sensitization of multiple defense pathways, yet none of the investigated pathways are required for the reduced-HR phenotype.
\end{abstract}

Additional keywords: Arabidopsis thaliana, AtCNGC2, AtCNGC4, HLM1, P. syringae pv. tomato DC3000, RPS2.

Plants have numerous defenses against pathogen attack, some of which are constitutive while others are induced by contact with the pathogen. Specific recognition of pathogens can occur via direct or indirect interaction of the products of host resistance $(R)$ genes with corresponding pathogen avirulence (avr) gene products (Jones and Dangl 2006; Nimchuk et al.

Corresponding author: A. F. Bent; Telephone: +1.608.265.3034; Fax: +1.608.263.2626; E-mail: afbent@wisc.edu

Ruth Genger and Grace Jurkowski contributed equally to this work.

Current address of $\mathrm{H}$. Lu: Department of Biology, University of Maryland-Baltimore County, Baltimore 21250, U.S.A.
2003). This "gene-for-gene" recognition rapidly induces an array of host defense responses, through signaling pathways that include cellular ion fluxes, production of reactive oxygen intermediates, mitogen-activated protein kinase cascades, and accumulation of salicylic acid (SA), with contributions from many signaling proteins (Glazebrook 2005; Hammond-Kosack and Parker 2003; Jones and Dangl 2006; Nimchuk et al. 2003). Compatible interactions in which host or pathogen lack the cognate $R$-avr gene exhibit similar, albeit slower and weaker, defense-associated changes in gene expression (Lucas 1998; Tao et al. 2003). It is of interest to understand the signaling mechanisms that activate inducible plant defense responses.

A characteristic feature of $a v r-R$-mediated resistance is the hypersensitive response (HR) - the programmed cell death of a small number of host cells at the site of pathogen attack (Greenberg and Yao 2004; Heath 2000). Although the HR has been hypothesized to limit access of biotrophs to host resources, several studies have indicated that the HR can be separated from other aspects of $a v r-R$-mediated resistance (Bendahmane et al. 1999; del Pozo and Lam 1998; Jakobek and Lindgren 1993; Kohm et al. 1993; Yu et al. 1998, 2000). The HR apparently can contribute to defense through death of the host cell or by contributing to the activation of defense in adjacent cells and to the activation of systemic acquired resistance (SAR) throughout the plant (Heath 2000).

We previously isolated Arabidopsis $d n d 1$ and $d n d 2$ mutants that exhibit a "defense, no death" phenotype (Yu et al. 1998, 2000). These plants carry out $a v r-R$-mediated defense responses despite substantial absence of the HR but also exhibit constitutively elevated SA levels, reduced plant size, and elevated broad-spectrum disease resistance (Yu et al. 1998, 2000). The dndl and $d n d 2 / h l m l$ mutations carry stop codons that disrupt the cyclic nucleotide-gated ion channel proteins AtCNGC2 and AtCNGC4, respectively (Balague et al. 2003; Clough et al. 2000; Jurkowski et al. 2004). A separate Arabidopsis cpr22 mutation caused fusion of two other cyclic nucleotide-gated ion channel proteins, AtCNGC11 and AtCNGC12 (Yoshioka et al. 2006). The cpr22 plants exhibit constitutive defense signaling and $\mathrm{Ca}^{2+}$-dependent programmed cell death; however, unlike the $d n d / h l m$ mutants, they still develop a normal HR, and single-gene knockouts of AtCNGC11 or AtCNGC12 do not confer $d n d$-like phenotypes (Balague et al. 2003; Clough et al. 2000; Jurkowski et al. 2004; Urquhart et al. 2007; Yoshioka et al. 2001, 2006). Impacts of these ion channel mutations on defense are not surprising given the importance of ion fluxes in plant defense signaling (Nurnberger and Scheel 2001); however, the means by which the $d n d$ and other CNGC mutants alter defense remain unclear. 
AtCNGC2 and AtCNGC4 are more closely related to each other than to other Arabidopsis CNGCs (Maser et al. 2001) but the two genes are functionally nonredundant, in that loss of either can cause $d n d$ phenotypes. They may, however, form a heterotetramer ion channel, as is known to occur with animal CNGC channels (Zhong et al. 2003). Study of AtCNGC2 and AtCNGC4 has demonstrated conductance of $\mathrm{Ca}^{2+}$ and $\mathrm{K}^{+}$but not $\mathrm{Na}^{+}$by AtCNGC2 (Ali et al. 2007; Hua et al. 2003; Leng et al. 1999, 2002; Tornero and Dangl 2001), and conductance of $\mathrm{K}^{+}$and $\mathrm{Na}^{+}$by AtCNGC4 (Balague et al. 2003). AtCNGC2 and AtCNGC4 have different binding affinities for calmodulin isoforms, suggesting differential regulation of channel activity (Kohler and Neuhaus 2000). Additionally, expression of these genes is differentially regulated, because $A t C N G C 2$ is constitutively expressed regardless of treatment while AtCNGC4 is induced by treatment with avirulent Xanthomonas spp. or with methyl-jasmonate (Balague et al. 2003). Studies using transgenic $d n d 1$ and $d n d 2$ plants expressing bacterial salicylate hydroxylase $\left(n a h G^{+}\right)$, which catabolizes SA, suggested that SA is required for the elevated resistance of $d$ nd mutants but not for the loss of HR (Clough et al. 2000; Jurkowski et al. 2004). $P A D 4$ is also required for elevated resistance in dndl and dnd2/hlml but not for other phenotypes of these mutants (Jirage et al. 2001).

A number of components of plant defense pathways have been revealed by analysis of Arabidopsis mutants with increased disease susceptibility. NDRl, for example, is required for the function of many $\mathrm{R}$ proteins that possess coiled-coil, nucleotidebinding site leucine-rich repeat domains (NB-LRR), whereas many $\mathrm{R}$ proteins with an $\mathrm{N}$-terminal domain homologous to Toll and the interleukin-1 receptor (TIR-NB-LRR) require EDS1 and PAD4 (Aarts et al. 1998; Feys et al. 2001), defining at least two separate pathways for defense signaling. The existence of a third pathway is indicated by the finding that the RPP7 and RPP8 genes for resistance to Hyaloperonospora parasitica activate defenses independently of EDSI and NDRI (McDowell et al. 2000). Two very important classes of mutants with enhanced disease susceptibility include eds5/sidl and eds16/sid2, which are impaired in SA accumulation (Nawrath and Metraux 1999; Rogers and Ausubel 1997; Volko et al. 1998), and nprl/niml, which fail to respond to exogenously applied SA (Cao et al. 1994; Delaney et al. 1995; Shah et al. 1997). SA is involved in $a v r-R$-mediated defenses and it is required for establishment of SAR and for basal resistance to some virulent pathogens (Cao et al. 1994; Nawrath and Metraux 1999). Mutant $n d r l$ plants exhibit a partial reduction in SA accumulation after infection (Shapiro and Zhang 2001), whereas EDS16/SID2 encodes isochorismate synthase, a central protein in SA biosynthesis whose absence largely eliminates SA production (Wildermuth et al. 2001). NPRl acts downstream of SA to mediate activation of defense genes (Cao et al. 1994; Delaney et al. 1995; Pieterse and Van Loon 2004) and also influences SA levels, which are often elevated in nprl plants (Ryals et al. 1996; Shah et al. 1997). However, some SA-dependent defense responses are independent of NPRI (Bowling et al. 1997; Glazebrook et al. 1996; Rate et al. 1999).

Analysis of Arabidopsis mutants impaired in jasmonic acid (JA) or ethylene biosynthesis or perception has revealed that these two signaling molecules act in concert to induce plant defenses against necrotrophic pathogens (Balbi and Devoto 2008; Knoester et al. 1999; Lorenzo et al. 2003; Penninckx et al. 1998; Staswick et al. 1998; Thomma et al. 1999). For example, the resistance of Arabidopsis against the pathogens Pseudomonas syringae and $H$. parasitica is known to be mediated primarily through SA-mediated signaling pathways rather than JA or ethylene pathways whereas, in contrast, defense against Botrytis cinerea is mediated primarily through JA or ethylene pathways
(Balbi and Devoto 2008; Feys and Parker 2000; Pieterse and Van Loon 2004; Spoel et al. 2003; Thomma et al. 1999); there is also a small contribution to defense against $B$. cinerea from basal SA accumulation not involving SID2-mediated SA biosynthesis (Ferrari et al. 2003; Govrin and Levine 2002). There is evidence of crosstalk between ethylene and JA responses. For example, expression of some JA-responsive genes is antagonized by ethylene (Ellis and Turner 2001; Rojo et al. 1999) and promotion of ozone-induced cell death by ethylene is antagonized by JA (Overmyer et al. 2000, 2003; Tuominen et al. 2004). There is also complex and biologically significant crosstalk between SA-dependent and JA- or ethylene-dependent defense pathways that, for example, can lead to NPR1-mediated suppression of JA signaling and defenses (Balbi and Devoto 2008; Feys and Parker 2000; Pieterse and Van Loon 2004; Spoel et al. 2003). Crosstalk between pathways leading to defense and stress responses likely serves to fine-tune plant responses to multiple biotic and abiotic stresses.

In the present study we used epistasis analysis to examine the contributions of NPRI-, SID2-, NDR1-, and EIN2-associated pathways to expression of the distinct defense phenotypes that arise in $d n d 1$ and $d n d 2$ mutants. Introduction of nprl, $n d r 1$, sid2, or ein2 impacted some but not all of the $d n d$ phenotypes, and unanticipated redirection of defense signaling was observed.

\section{RESULTS}

Morphology of double mutants carrying $d n d 1$ or $d n d 2$.

Morphologically, $d n d 1$ and $d n d 2$ plants exhibit dwarf rosettes compared with wild-type Columbia plants (Yu et al. 1998, 2000). We introduced mutations that perturb $R$ gene-mediated signaling $(n d r l)$, SA-mediated defense signaling (sid2 and nprl), or ethylene-mediated defense signaling (ein2) into the dnd 1 and $d n d 2$ backgrounds. The resulting plant lines were grown in numerous independent experiments, and a representative example of the reproducibly altered rosette morphology that was observed for some genotypes is provided in Figure 1. Homozygous npr1, sid2, ndr1, and ein2 single-mutant plants were similar to wild-type Columbia in size and appearance. None of these mutations, when introduced into the $d n d 1$ or $d n d 2$ backgrounds, completely reversed the dwarf phenotype. However, the $n d r l$ and the sid2 mutations slightly but consistently relieved the dwarf rosette size of $d n d 1$ and $d n d 2$ plants (Fig. 1A and B). In contrast, dndl nprl lines exhibited an exacerbation of the dwarf rosette phenotype (Fig. 1A). The dndl nprl plants also displayed macroscopic spontaneous lesions in the absence of pathogen and a wrinkled leaf phenotype (Fig. 1C). Unlike the effects seen in the $d n d l$ background, introduction of $n p r l$ into the $d n d 2$ genetic background partially relieved the dwarf rosette phenotype, and $d n d 2$ nprl plants did not exhibit spontaneous lesions or wrinkled leaves (Fig. 1D). Introduction of the ein 2 mutation into the $d n d 1$ and $d n d 2$ backgrounds did not alter the dwarf phenotype (Fig. 1A and 1D). Triple-mutant $d n d 1$ nprl ein 2 and $d n d 2$ nprl ein 2 plants were similar in size to $d n d 1$ and $d n d 2$ single-mutants, respectively, although, like nprl ein2 plants, their color was a more pale green than wild-type or $d n d$ plants (Fig. 1D). These triple mutants exhibited ruffled leaf edges.

\section{NPR 1 -independent expression of $\boldsymbol{\beta}$-glucanase- 2 .}

The nprl-1 genetic background used to construct double mutants in this study contains a $\beta$-glucanase (GUS) transcriptional reporter fusion (BGL2::GUS); nprl-1 plants fail to induce $B G L 2:: G U S$ expression in response to exogeneous application of SA (Cao et al. 1994). We noted strong GUS staining in dndl nprl and dnd2 nprl plants in the absence of pathogens 
A

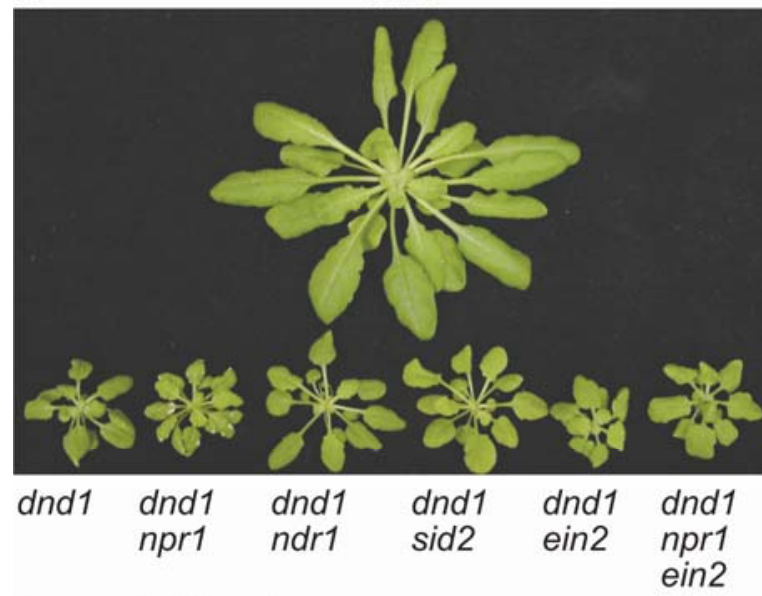

B dnd1 npr1

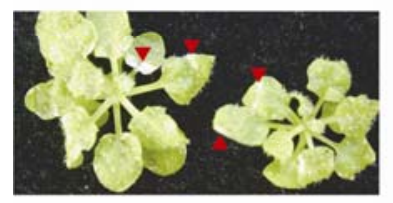

C Col-0

$\operatorname{sid} 2$
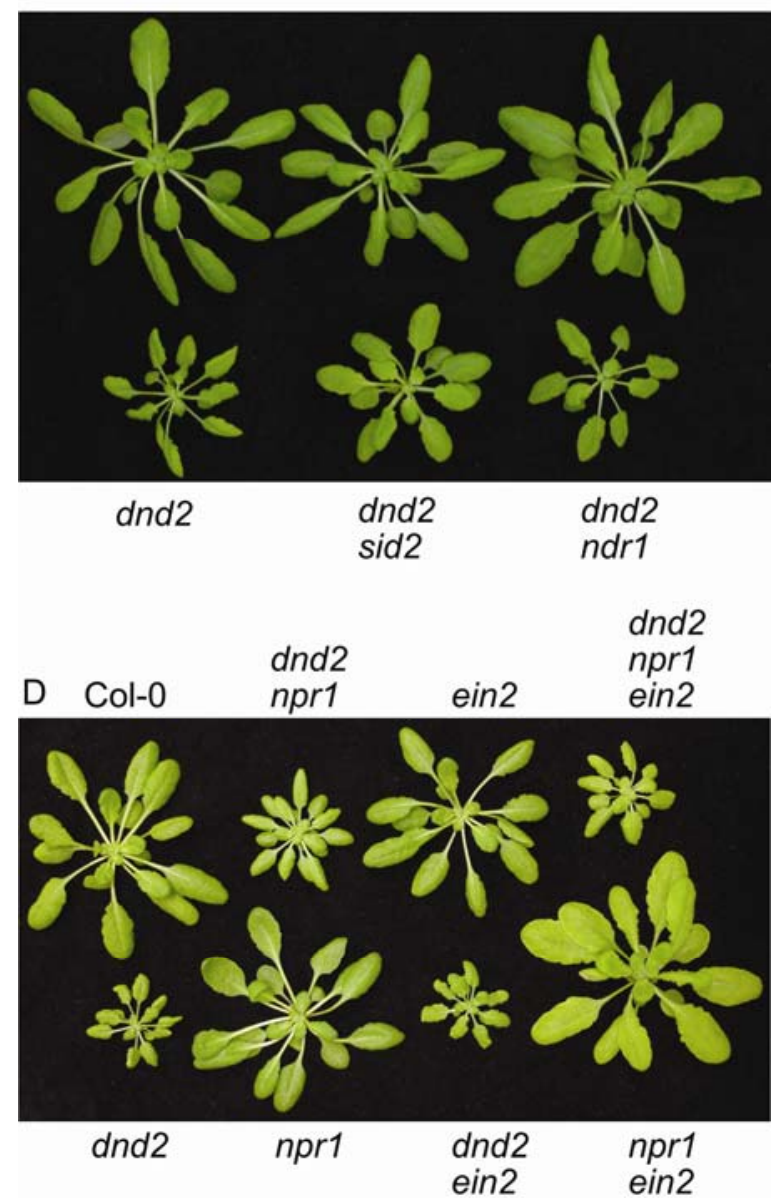

Fig. 1. Effect of various mutations on the rosette morphology of $d n d 1$ and $d n d 2$ plants. A, Two-month-old $d n d 1$ and double mutant plants. B, Spontaneous lesions on 2-month-old dndl nprl plants. Some lesions are indicated with red arrows. C, Five week old $d n d 2$, $d n d 2 \operatorname{sid} 2$, and $d n d 2 n d r 1$ plants. D, Five-week-old $d n d 2$ plant with double mutants $d n d 2$ nprl and dnd 2 ein 2 , and triple mutant $d n d 2$ nprl ein 2 . and without SA application, showing that mutations in $d n d 1$ and $d n d 2$ activate $B G L 2(P R-2)$ via an NPRl-independent pathway (Fig. 2A and B).

SA production in $\boldsymbol{d n d}$ nprl and $\boldsymbol{d n d}$ sid 2 double mutants.

Leaves of $d n d 1$ and $d n d 2$ mutants accumulated high levels of SA (Jurkowski et al. 2004; Yu et al. 1998). We measured SA for $d n d 1$ and $d n d 2$ mutants carrying mutations in $n p r l$, sid2, $n d r 1$, or ein2. As expected, levels of total SA in the $d n d 1$ or $d n d 2$ background were markedly reduced when the sid2 mutation, which significantly impairs SA biosynthesis, was present (Fig. 3). A much smaller effect was seen for free SA (Fig. 3), and we noted that the $d n d$ mutants exhibited SID2-independent production of SA. In both the $d n d 1$ and $d n d 2$ backgrounds, the presence of the $n p r l$ mutation correlated with a large increase in SA to levels higher than those seen for nprl, suggesting impacts on SA feedback regulation (discussed below). The effect of the $n d r 1$ mutation was less clear. In one of two experiments, levels of both conjugated and free SA were lower in $d n d 1$ ndrl than in $d n d 1$; however, plants in the other experiment showed little to no effect of the $n d r l$ mutation on total or free SA in either the $d n d 1$ or $d n d 2$ background. As expected, the ein $2 \mathrm{mu}-$ tation had little to no effect on SA levels in either $d n d 1$ or $d n d 2$ (Fig. 3).

\section{HR phenotype of $d n d$ plants is not relieved} by $n p r 1, n d r 1$, sid2, or ein2.

The $d n d$ mutants were isolated in a mutant screen for plants that failed to exhibit the HR in response to high titer of $P$. sy-
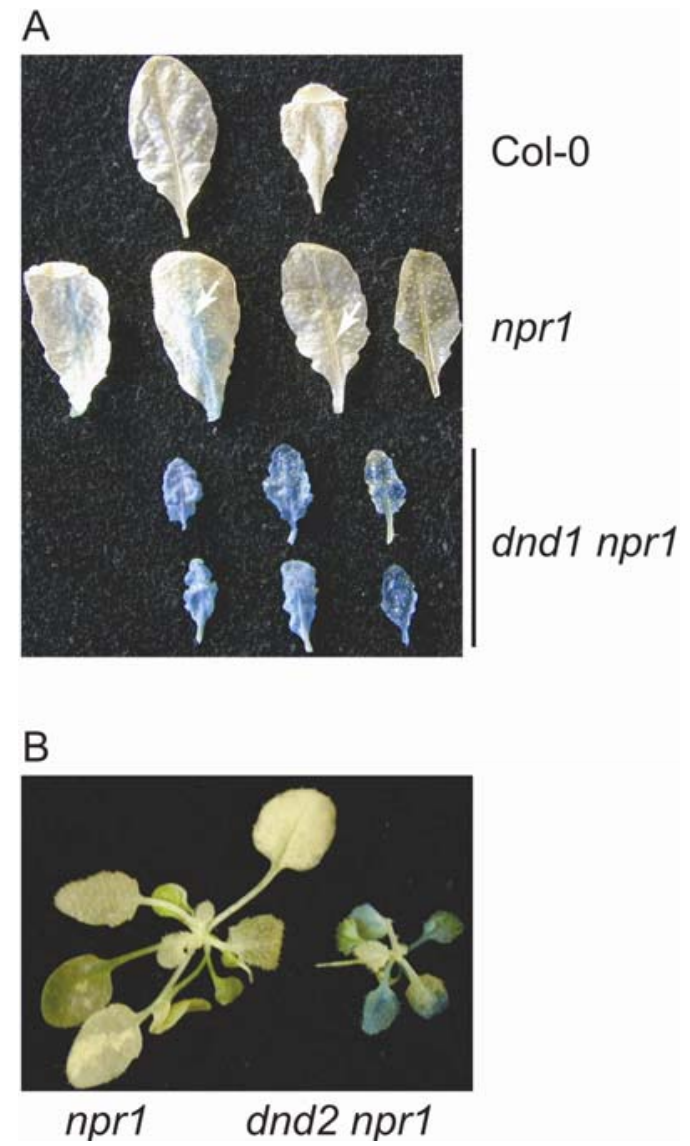

Fig. 2. $\beta$-Glucanase (GUS) expression phenotypes of single and double mutants. Mutants nprl, dnd 1 nprl, and dnd 2 nprl carry the $B G L 2$ promoter region fused to the $\beta$-glucuronidase reporter gene. $\mathbf{A}$, Constitutive expression of $B G L 2:: G U S$ in leaves of noninoculated $d n d 1 \mathrm{nprl}$ plants. B, Constitutive expression of $B G L 2:: G U S$ in noninoculated $d n d 2$ nprl plants. 
ringae pv. glycinea race 4 expressing avrRpt2 (Yu et al. 1998, 2000). We conducted a similar assay by inoculating $d n d l$ and $d n d 2$ double mutants and single-mutant parents with $P$. syringae pv. glycinea race 4 expressing avrRpt 2 at $1 \times 10^{8} \mathrm{CFU} / \mathrm{ml}$ and assessing $\mathrm{HR}$ at $24 \mathrm{~h}$. As expected, wild-type Columbia and the mutants $n p r 1$, sid2, ein2, and nprl ein2 exhibited a strong HR, whereas a weak or intermediate HR was observed for $n d r l$ mutants. Mutant plants of $d n d 1, d n d 2$, and their double mutants with $n p r 1$, sid2, ein2, and $n d r 1$, as well as the triple mutants dnd1 nprl ein2 and dnd2 nprl ein2, did not show an HR (Table 1). Thus, mutation of NPR1, SID2, NDR1, or EIN2 did not relieve the loss-of-HR phenotype of the $d n d$ mutants.

\section{Distinct impacts of npr1, sid2, and ndr1 on growth of $P$. syringae pv. tomato.}

Impacts of the nprl, sid2, ein2, and ndrl mutations on the defense responses of $d n d$ mutants were further examined by measuring the growth of virulent $P$. syringae pv. tomato DC3000 (DC3000) or avirulent DC3000 expressing avrRpt2 (Fig. 4). The sections of Figure 4 identify instances in which there were significant differences between host genotypes in the amount of bacterial growth observed, as determined by analysis of variance (ANOVA) for the combined data from
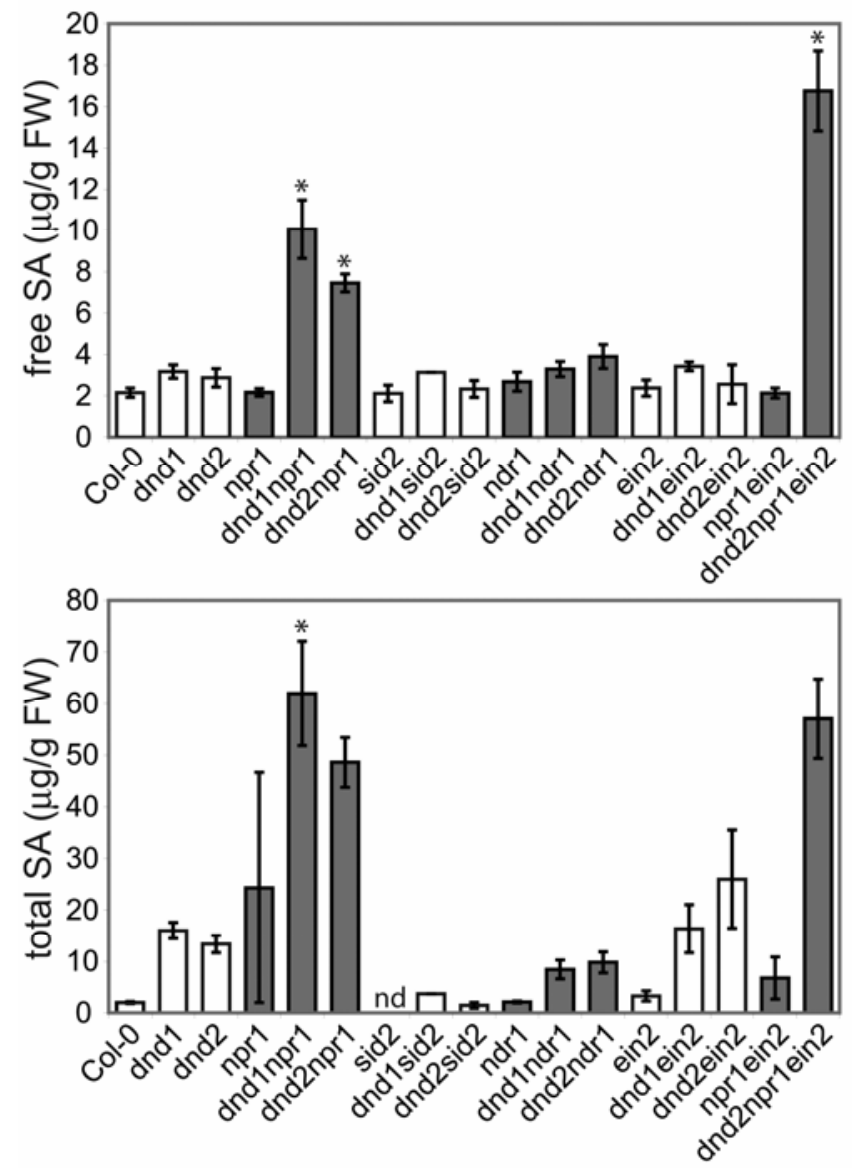

Fig. 3. Salicylic acid (SA) levels in single, double, and triple mutants. Free (unconjugated) and total SA in leaves of 4-week-old plants. Four replicates were measured for each genotype within each experiment; error bars represent standard error of the mean. Similar genotypes are grouped by shading; asterisks denote plant lines for which SA levels were significantly different from the parental line that is left-most within the similarly shaded group of bars (analysis of variance $P<0.05$; Tukey test). Similar results were obtained in a second, independent experiment; nd = not detectable. three or more independent experiments. As previously reported, populations of both virulent and avirulent DC3000 were restricted in leaves of $d n d 1$ and $d n d 2$ mutants relative to wildtype Columbia (Yu et al. 1998, 2000).

The ability of $d n d 1$ and $d n d 2$ plants to restrict bacterial growth was compromised by $n p r 1$; levels of both virulent and avirulent DC3000 were significantly higher in leaves of $d n d 1$ $n p r 1$ and $d n d 2$ nprl than in $d n d 1$ and $d n d 2$, respectively (Fig. $4 \mathrm{~A}$ and B). Double mutants carried bacterial populations similar to those found in the nprl single mutant except in the case of $d n d 2$ nprl plants inoculated with virulent bacteria (Fig. 4A and B), suggesting that NPRl-independent defense pathways partially contribute to the enhanced resistance of $d n d 2$ plants to virulent DC3000.

Restriction of growth of virulent and avirulent $P$. syringae pv. tomato DC3000 was entirely dependent on SID2 for both $d n d 1$ and $d n d 2$. Interestingly, growth of DC3000 expressing avrRpt 2 was higher in leaves of $d n d 1$ sid 2 and $d n d 2$ sid 2 than in leaves of sid2 alone (Fig. 4C and D).

The $n d r 1$ mutation, which impairs resistance mediated by RPS2, RPM1, and RPS5 (Century et al. 1995), disrupted the ability of both $d n d 1$ and $d n d 2$ to restrict growth of DC3000 expressing avrRpt2 (Fig. 4E and F). Intriguingly, the $n d r l$ mutation also impacted resistance against virulent DC3000 in $d n d 2$ plants. DC3000 growth was similar in $d n d 1$ and dndl ndrl plants (Fig. 4E). However, in $d n d 2$ ndrl plants, DC3000 population sizes were reproducibly intermediate between those found in $d n d 2$ leaves and those in $n d r l$ leaves (Fig. 4F). The elevated restriction of virulent DC3000 caused by $d n d 2$ exhibits a partial dependence on NDRl that is not seen for $d n d l$.

Impairment of ethylene responses by the ein 2 mutation did not detectably alter the ability of $d n d 1$ or $d n d 2$ to restrict bacterial growth. In $d n d 1$ ein 2 and $d n d 2$ ein 2 leaves, virulent and avirulent $P$. syringae pv. tomato DC3000 numbers were restricted to levels similar to those in $d n d 1$ and $d n d 2$ leaves, respectively (Fig. 4G and $\mathrm{H}$ ). In a separate set of experiments that focused on triple mutants, although $d n d 1$ plants did restrict growth of avirulent DC3000 to a greater extent than dnd1 ein2, loss of EIN2 again did not observably alter bacterial growth for the other host and bacterial genotypes (Fig. 4I

Table 1. Hypersensitive response (HR) of $d n d 1$ and $d n d 2$ mutants in combination with mutations in $n p r 1, n d r 1, \operatorname{sid} 2$, and $e i n 2^{\mathrm{a}}$

\begin{tabular}{|c|c|c|}
\hline Genotype (no. of experiments) & HR (avrRpt2 $\left.{ }^{+}\right)$ & HR (no avr) \\
\hline Col-0 (3) & + & - \\
\hline dndl (3) & - & - \\
\hline dnd2 (2) & - & - \\
\hline$n p r 1(3)$ & + & - \\
\hline dnd1 nprl (1) & - & - \\
\hline dnd2 nprl (3) & - & - \\
\hline$n d r 1(3)$ & \pm & - \\
\hline dnd1 ndr1 (2) & - & - \\
\hline$d n d 2$ ndrl (2) & - & - \\
\hline $\operatorname{sid} 2(3)$ & + & - \\
\hline dnd1 sid2 (2) & - & - \\
\hline dnd2 sid2 (2) & - & - \\
\hline $\operatorname{ein} 2(2)$ & + & - \\
\hline dnd1 ein 2 (1) & - & - \\
\hline$d n d 2$ ein $2(2)$ & - & - \\
\hline npr1 ein2 (3) & \pm & - \\
\hline dnd1 nprl ein2 (1) & - & - \\
\hline dnd2 nprl ein2 (2) & - & - \\
\hline
\end{tabular}

a One-month-old plants were vacuum infiltrated with Pseudomonas syringae pv. glycinea race 4 at $10^{8} \mathrm{CFU} / \mathrm{ml}$ expressing avrRpt2 (avrRpt $\left.2^{+}\right)$or carrying an empty plasmid vector (no avirulence [no $a v r]$ ). Summarized scores from multiple experiments using a 0 -to-5 scale: 0 to $1.9=-, 2$ to $2.9= \pm, 3$ to $3.9=+$, and 4 to $5=++$. 
and $\mathrm{J}$ ). As one way to address whether the NPRI-independent defenses of $d n d$ plants are activated through JA or ethylene pathways, we constructed dnd nprl ein2 triple mutants but saw no further effect. With virulent and avirulent DC3000 bacteria, leaf population levels were similar in dnd npr1 ein2 triple mutants and $d n d$ nprl double mutants (Fig. 4I and J).
A

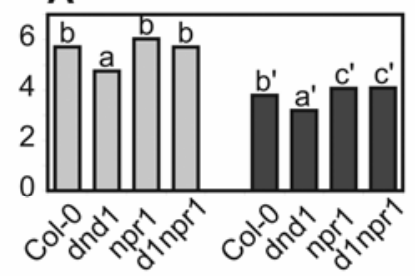

\section{B}
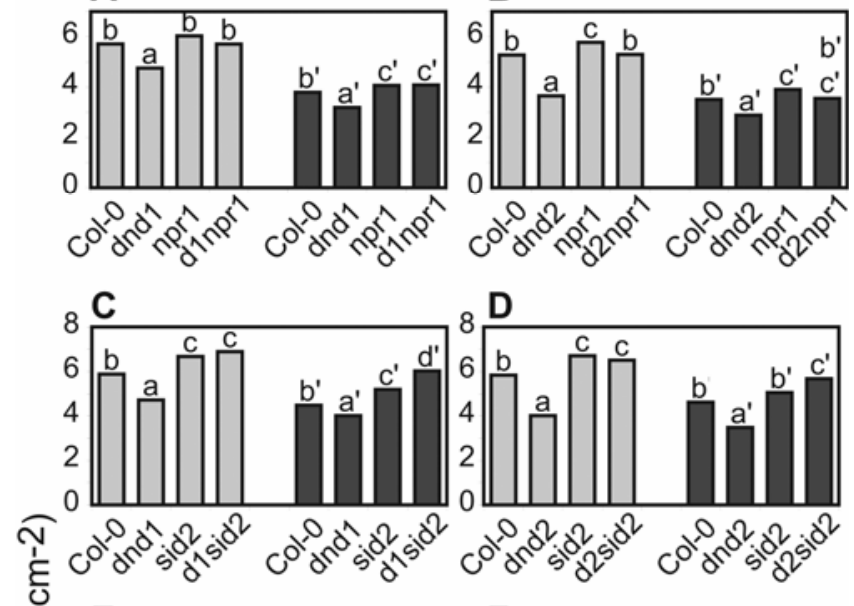

$\mathbf{F}$

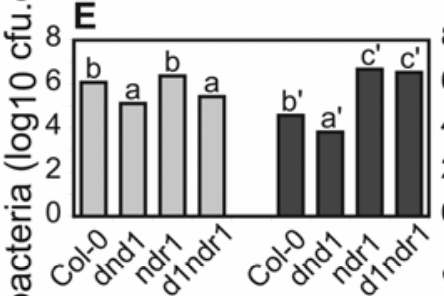

G

$\underset{1}{\square}$
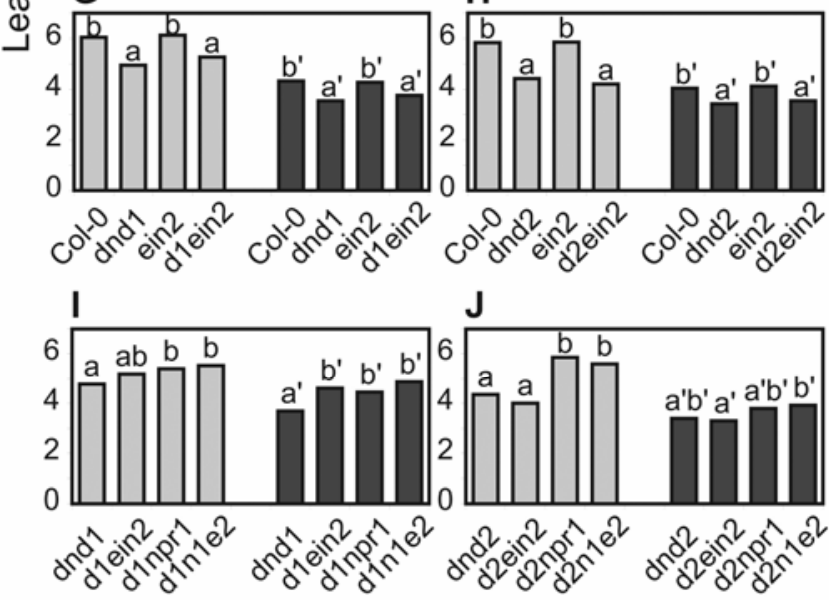

$\mathrm{J}$

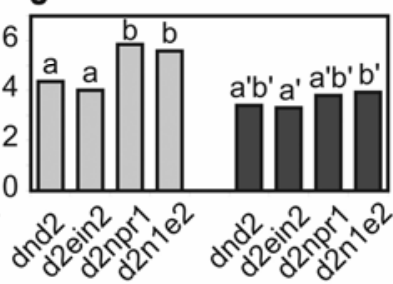

Fig. 4. Bacterial populations in leaves of single, double, and triple mutant plants. Leaf bacterial populations were determined 3 days after plants ( 4 to 5 weeks old) were inoculated by vacuum infiltration with Pseudomonas syringae pv. tomato DC3000 (light gray bars) at $5 \times 10^{4} \mathrm{CFU} / \mathrm{ml}$ or DC3000 + avrRpt2 (dark bars). Least squares means from the indicated number of independent experiments are presented. Within each set of four genotypes treated with the same bacterial strain, bars marked with the same letter were not significantly different (analysis of variance $P<0.05$ ). Data are from a total of 17 experiments, and wild-type Columbia was included in 16 of these experiments. Genotypes tested in comparison with wild-type and single-mutant controls were $\mathbf{A}$, dndl nprl (three experiments); B, dnd2 nprl (four experiments); C, dnd1 sid2 (three experiments); $\mathbf{D}, d n d 2 s i d 2$ (four experiments); $\mathbf{E}, d n d 1$ ndrl (three experiments); $\mathbf{F}$, $d n d 2$ ndr1 (three experiments); G, $d n d 1$ ein2 (five experiments); $\mathbf{H}$, dnd2 ein2 (seven experiments); J, dnd1 npr1 ein2 (four experiments); and $\mathbf{K}$, dnd2 npr1 ein2 (three experiments). In figure labels, genotypes are abbreviated as follows: $\mathrm{d} 1=d n d 1 ; \mathrm{d} 2=d n d 2 ; \mathrm{d} 1 \mathrm{n} 1 \mathrm{e} 2=$ dnd1nprlein 2 ; and $\mathrm{d} 2 \mathrm{n} 1 \mathrm{e} 2=$ dnd2nprlein 2 .

\section{Altered chlorotic responses}

to $P$. syringae pv. tomato in $d n d 1$ double mutants.

Pathogen population size and disease damage to the host (symptoms such as chlorosis and cell death) do not always correlate. We monitored the development of disease symptoms in dndl double mutants inoculated by vacuum infiltration with either virulent $P$. syringae pv. tomato DC3000 or DC3000 expressing avrRpt2. As previously observed in many laboratories, wild-type Columbia plants inoculated with virulent DC3000 first exhibited chlorosis approximately 3 days after inoculation (not shown), and more successfully limited disease damage relative to immunocompromised genotypes such as sid2 or nprl (Fig. 5). Note that, in two other experiments, sid2 plants inoculated with DC3000 expressing avrRpt2 exhibited more evident chlorosis on their leaves than is shown in the experiment of Figure 5. As expected from previous studies, dndl plants inoculated with either virulent or avirulent DC3000 remained asymptomatic up to and beyond 7 days after inoculation, indicating significant resistance even in the absence of an avr-R interaction (Fig. 5).

Although bacterial growth in double-mutant dndl nprl plants was high, as in nprl mutants (Fig. 4), disease symptoms of dndl nprl plants were more like $d n d l$ plants, with only minimal chlorosis or other disease symptoms after inoculation with either virulent or avirulent DC3000 (Fig. 5). In contrast,
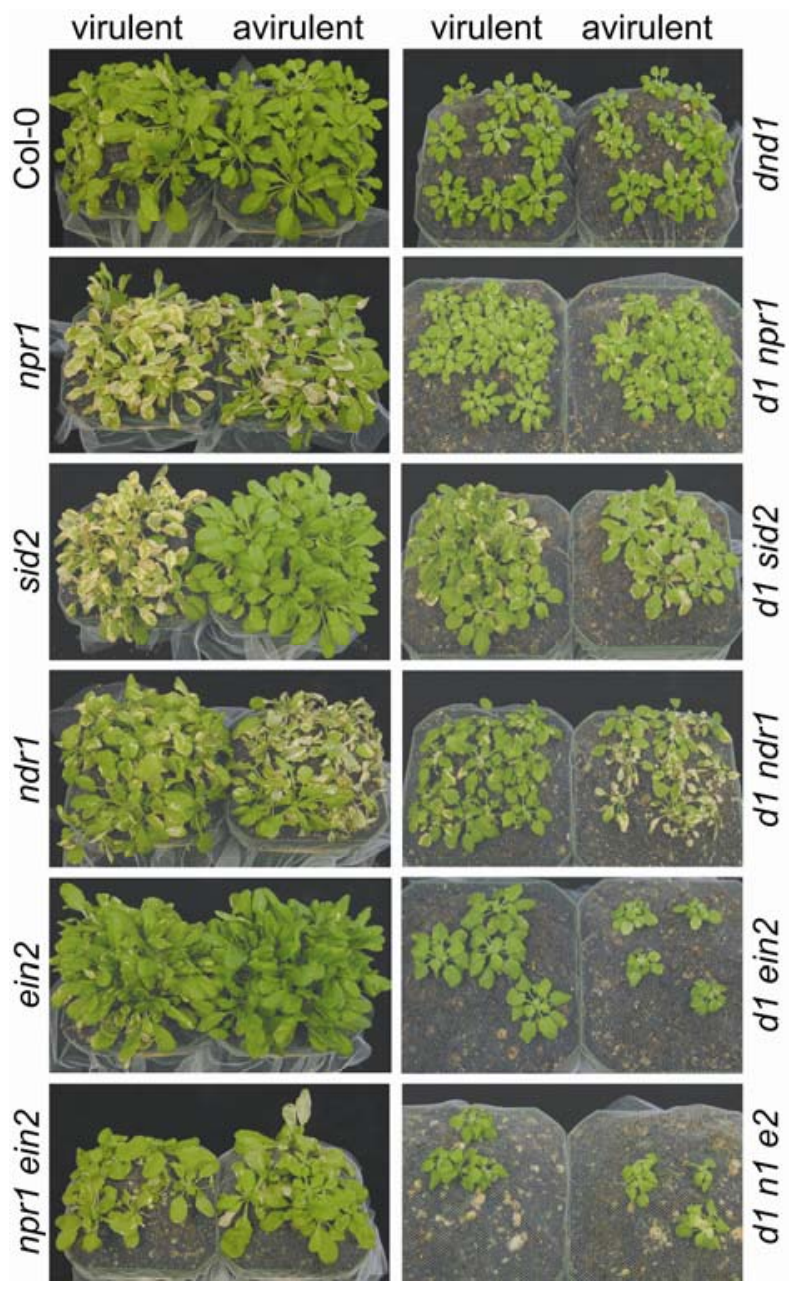

Fig. 5. Disease symptoms in double and triple mutants. Two-month-old $d n d l$ double or triple mutant plants 7 days after inoculation with Pseudomonas syringae pv. tomato DC3000 \pm avrRpt $2\left(2 \times 10^{5} \mathrm{CFU} / \mathrm{ml}\right)$ by vacuum infiltration. Chlorosis was evident 3 days postinoculation in susceptible lines. This experiment was repeated three times with similar results. 
dnd1 sid2 plants, like sid2 plants, developed chlorosis after inoculation with virulent or avirulent DC3000 (Fig. 5). These results suggest that $d n d 1$ mutants suppress symptom development in an NPRI-independent manner; however, this suppression may require elevated SA levels. The $n d r l$ plants exhibited chlorosis (similar to wild-type plants) when inoculated with virulent DC3000 but severity of chlorosis was significantly greater when inoculated with DC3000 expressing avrRpt2 (Fig. 5) (Century et al. 1995). The pattern of chlorosis seen for dnd1 ndrl plants in response to virulent and avirulent DC3000 was comparable with that seen for $n d r l$ (Fig. 5).

The dndl mutants and the dndl ein 2 double mutants were quite similar in overall symptom development in response to either virulent or avirulent DC3000 (Fig. 5). Likewise, dndl nprl and dndl nprl ein 2 plants showed similar symptom development. This is consistent with our overall observations that ein2 has minimal impact on $d n d$ phenotypes. Double-mutant nprl ein2 plants developed much less chlorosis than $n p r 1$ single mutants, providing a particularly pronounced example of the previous observation that ethylene insensitivity can enhance the disease tolerance of Arabidopsis, tomato, soybean, and Nicotiana spp. to P. syringae and other bacteria (Bent et al. 1992; Hoffman et al. 1999; Knoester et al. 1998; Lund et al. 1998).

\section{SA-dependent, NPR1-independent PR-1 expression.}

Replicated RNA blot analyses were conducted to assess how $n p r 1$, sid2, ndrl, and ein2 mutations alter $d n d$-associated expression of $P R-1$ and $P D F 1.2$, standard marker genes for SAdependent and JA- or ethylene-dependent defense responses, respectively. As previously reported, both $d n d 1$ and $d n d 2$ exhibited constitutive $P R-1$ expression in the absence of pathogens and greater $P R-1$ expression in response to avirulent $P$. syringae pv. tomato (Fig. 6) (Jurkowski et al. 2004; Yu et al. 1998). Also as expected, single mutants nprl, sid2, and $n d r l$ failed to show substantial levels of $P R-1$ gene expression $24 \mathrm{~h}$ after inoculation whereas ein2 plants resembled wild-type Columbia (Fig. 6). In double mutants, the constitutive $P R-1$ gene expression of $d n d 1$ plants was reduced but not eliminated by nprl, and no further induction was seen in response to avirulent DC3000 (Fig. 6). Expression of $P R-1$ was not detected for dnd1 sid2 plants even when inoculated with virulent or avirulent DC3000 (Fig. 6). Taken together, these data suggest that dndl mutation results in the activation of an SA-dependent, $N P R l$-independent pathway leading to $P R-1$ expression.

The $d n d l n d r l$ plants retained constitutive $P R-1$ gene expression similar to the $d n d 1$ single mutant (Fig. 6). No additional $P R-1$ induction was seen in infected $d n d l n d r l$ plants (Fig. 6). In replicated experiments involving ein2, $P R-1$ gene expression was essentially unchanged between $d n d l$ and $d n d l$ ein 2 plants or between $d n d 1$ nprl and dnd1 nprl ein 2 plants, providing another instance where ein 2 had little or no effect on dnd phenotypes (Fig. 6).

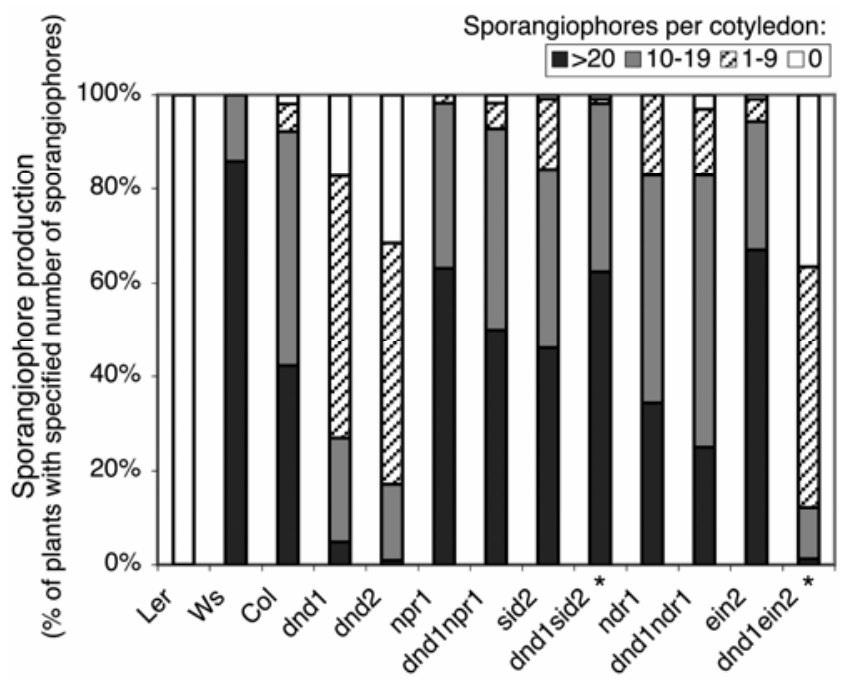

Fig. 7. Production of Hyaloperonospora parasitica sporangiophores on cotyledons of $d n d l$ double mutants 7 days after inoculation with Emco5 isolate. Data from two separate experiments are combined (total number of plants tested for each genotype ranged between 44 and 61). Asterisks designate double mutants that were significantly different from the corresponding non- $d n d l$ single mutant (e.g., dndl sid2 compared with sid2), determined by analysis of variance $(P<0.05$; Tukey test). Sporangiophore production on $d n d l$ was significantly different from all other genotypes except $d n d 1$ ein2.
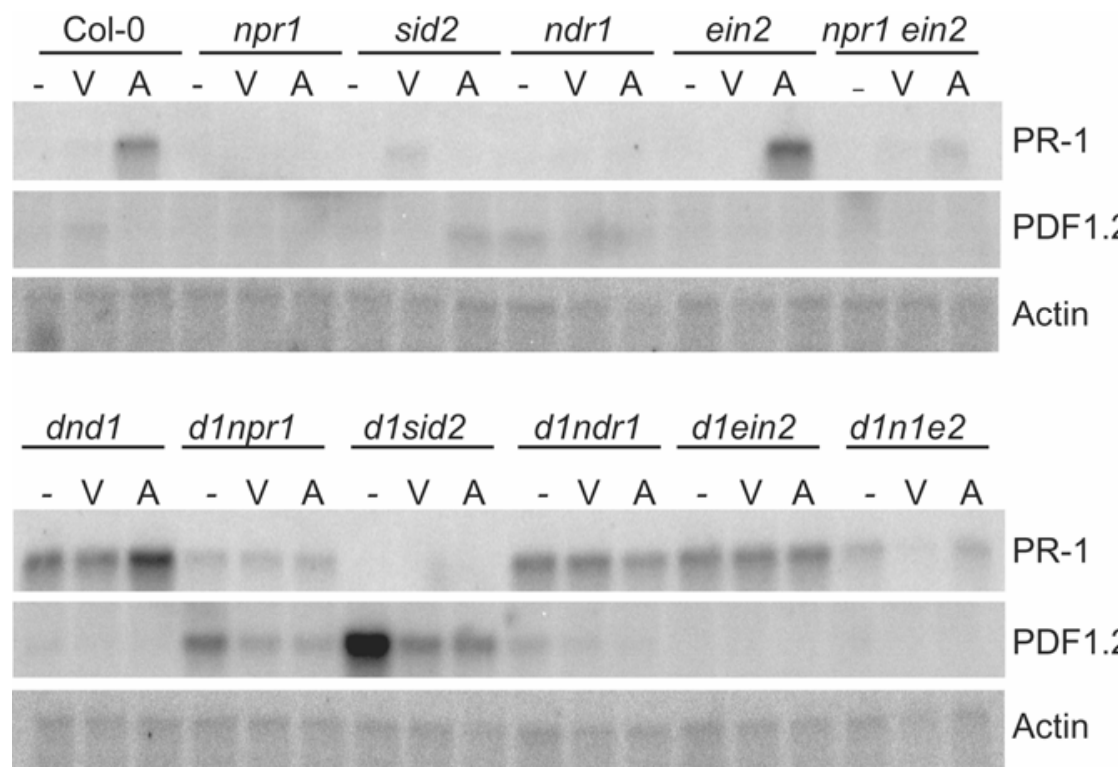

Fig. 6. $P R-1$ and $P D F 1.2$ expression in $d n d l$ double and triple mutants. Month-old plants either were not inoculated (-) or were inoculated by vacuum infiltration with $2 \times 10^{6} \mathrm{CFU}$ of Pseudomonas syringae pv. tomato DC3000 (V) or DC3000 avrRpt2 (A) per milliliter, and leaf tissue for RNA extraction was collected $24 \mathrm{~h}$ later. Actin served as a loading control. Similar results were obtained in independent experiments. 
PDF1.2 expression in $d n d 1$ is promoted if SA pathways are blocked and is suppressed by $P$. syringae pv. tomato $\mathrm{DC} 3000$ infection.

In light of the crosstalk that can occur between SA and JA or ethylene defense signaling, we also investigated how $d n d$ and the other mutations altered expression of PDF1.2. As expected from previous reports, RNA blot analyses did not reveal notable PDF1.2 expression in Columbia or in $n p r l$, sid2, $n d r l$, or ein2 mutants before or after inoculation with virulent or avirulent DC3000 (Fig. 6). We found that PDF1.2 expression was also minimal in $d n d 1$, dndl $n d r 1$, and $d n d 1$ ein 2 plants (Fig. 6). However, although $d n d 1$ plants did not exhibit constitutive PDF1.2 expression, substantial levels of PDF1.2 RNA were reproducibly observed in noninoculated $d n d 1$ nprl and $d n d l$ sid2 plants (Fig. 6). The observed PDF1.2 expression was partially EIN2 dependent, because it was reduced in dnd1 nprl ein2 plants. The constitutive defense signaling of $d$ nd mutants is apparently directed to JA or ethylene pathways when SA- or NPR1-mediated pathways are blocked. Of equal interest, in multiple replicates, the strong $P D F 1.2$ expression in noninoculated $d n d 1$ nprl and $d n d 1$ sid 2 plants was significantly reduced when plants were inoculated with either virulent $P$. syringae pv. tomato or avirulent $P$. syringae pv. tomato expressing avrRpt 2 (Fig. 6).

\section{Requirement for NPR1, SID2, and NDR1}

for $d n d 1$ resistance to virulent $H$. parasitica.

To further evaluate the disease resistance phenotypes of dndl double mutants, we inoculated seedlings with an isolate of the oomycete downy mildew pathogen $H$. parasitica (Emco5). The Landsberg erecta allele of RPP8 confers resistance to Emco5, whereas Columbia plants are susceptible to Emco5 and carry a nonfunctional allele of RPP8 (McDowell et al. 1998). Columbia $d n d 1$ plants exhibited strong resistance to this virulent isolate of $H$. parasitica, as expected (Yu et al. 1998), although this resistance was not as effective as that conferred by RPP8 (Fig. 7; c.f. Ler). This strong level of "com- patible interaction resistance" to Emco5 by $d n d 1$ plants was significantly compromised by introduction of $n p r 1$, sid2, or $n d r l$ into the $d n d 1$ genotype (Fig. 7). Notably, dndl sid2 plants supported significantly higher sporangiophore production than did sid2 plants (Fig. 7). In contrast, the dndl ein2 mutant retained the disease resistance phenotype of the $d n d 1$ parental line. These data indicate that NPR1, SID2, and NDR1, but not EIN2, are necessary for $d n d 1$-mediated resistance to virulent $H$. parasitica.

\section{Loss of resistance to $B$. cinerea in $d n d$ ein 2 is reversed by $n$ prl.}

To evaluate JA- or ethylene-mediated defense capacity in $d n d 1$ and $d n d 2$ mutants, we inoculated plants with the necrotrophic fungal pathogen $B$. cinerea. Govrin and Levine (2000) previously reported that the loss-of-HR dndl plants do not support $B$. cinerea growth; we also observed less $B$. cinerea growth on $d$ nd mutants relative to wild-type plants (Fig. 8). We noted a striking susceptibility to $B$. cinerea in $d n d 1$ ein 2 and dnd2 ein 2 plants compared with $d n d 1$ and $d n d 2$, respectively (Fig. 8), indicating a dependence on ethylene signaling for $d n d 1$ - and $d n d 2$-mediated resistance to $B$. cinerea. Note that dnd ein 2 double mutants retain the defective HR of $d n d$ mutants (Table 1).

Independently replicated RNA blot analyses showed strong $P D F 1.2$ expression in $d n d 1$ and $d n d 2$ plants challenged with B. cinerea (Fig. 9). No induction of PDF1.2 expression over that for mock-inoculated materials was seen for $d n d 1$ ein 2 or dnd2 ein2 plants infected with $B$. cinerea; however, elevated expression was seen in the $d n d 1$ and $d n d 2$ backgrounds in the presence of the $n p r l$, sid2, and $n d r l$ mutations (Fig. 9). Interestingly, although inoculated $d n d 1$ ein 2 and $d n d 2$ ein2 exhibited minimal PDF1.2 expression, expression was elevated in dnd1 nprl ein 2 and dnd2 nprl ein 2 mutants (Fig. 9). These triple mutants carrying a defective EIN2 were substantially more resistant to $B$. cinerea than ein2 singles or dnd ein2 double mutants (Fig. 8).

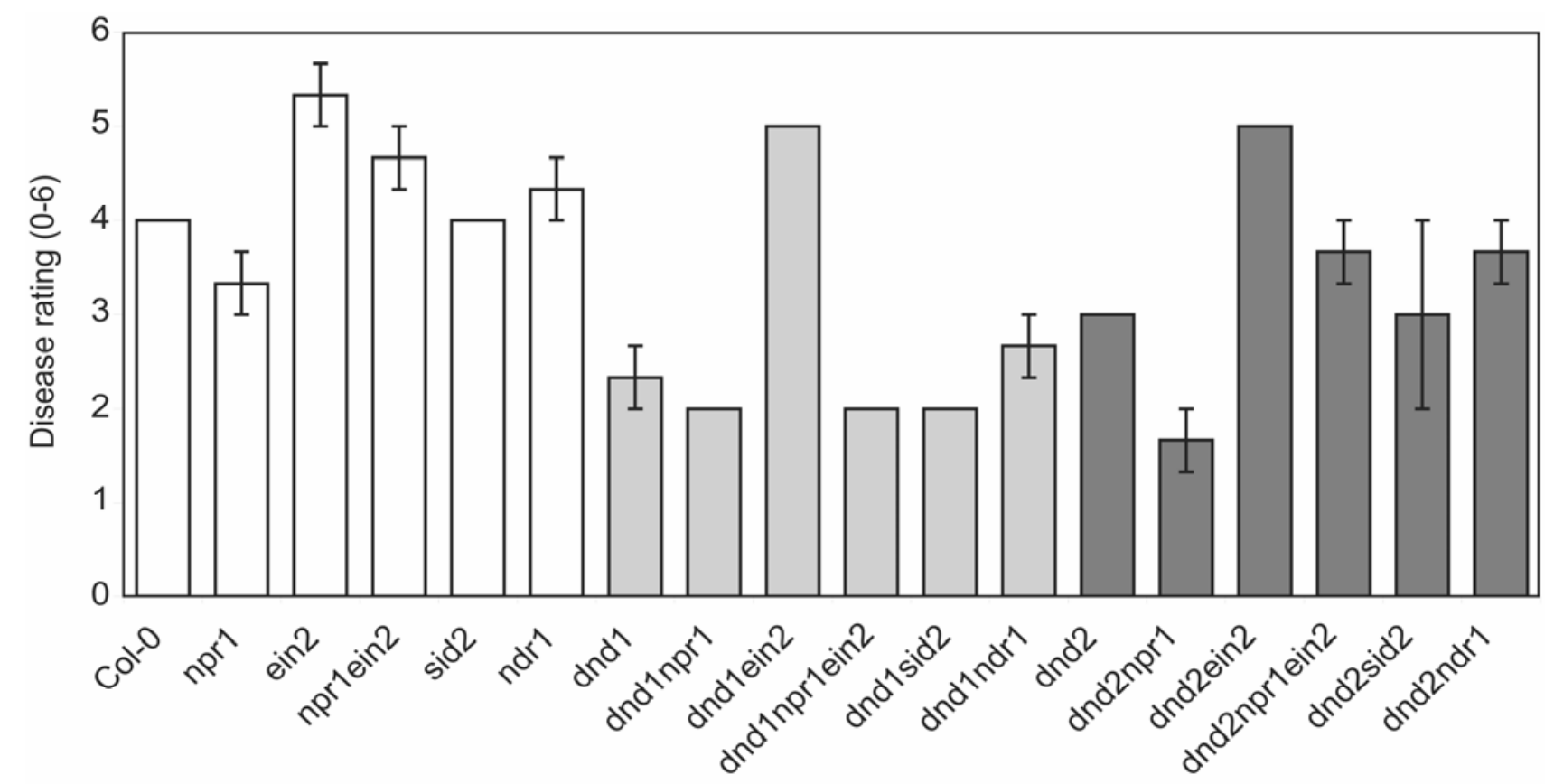

Fig. 8. Disease ratings of $d n d 1$ double and triple mutants inoculated with Botrytis cinerea. Two-month-old plants were inoculated with $B$. cinerea at $2 \times 10^{5}$ spores/ml and rated for disease symptoms 3 days postinoculation. Means \pm standard error (SE) of disease ratings from three independent experiments are shown for all lines except $d n d 1$ nprl ein2, which lacks SE data because only two replicates were completed. Asterisks identify severity scores that were significantly different from the left-most line with the same shading $(\mathrm{Col}-0$, $d n d 1$, or $d n d 2)$, determined by analysis of variance $(P<0.05$; Tukey test). Disease rating scale: $0=$ no disease to $6=$ extensive disease. 


\section{DISCUSSION}

Plants carrying mutations in DND1 (AtCNGC2) or DND2 (AtCNGC4, HLM1) show multiple phenotypes, including reduced or absent HR, dwarfing, enhanced resistance to virulent and avirulent pathogens, elevated SA levels, and constitutive expression of defense marker genes (Balague et al. 2003; Clough et al. 2000; Govrin and Levine 2000; Jirage et al. 2001; Jurkowski et al. 2004; Yu et al. 1998, 2000). It has been unclear how these cyclic nucleotide-gated ion channels and mutation of these channels are tied into normal defense pathways. Here, we identify some of the well-characterized defense pathways that mediate the enhanced resistance of $d n d l$ and $d n d 2$ mutants, and show that plant defense pathways are activated in interesting ways in $d n d$ double and triple mutants. Our findings reinforce the concept that plant defense is controlled by regulatory networks rather than linear pathways and that specific elements of the plant response (e.g., pathogen growth restriction, SA production, expression of defense-associated genes, disease lesions, HR, and dwarfing) are regulated in overlapping but partially separable ways.

The enhanced resistance of $d n d 1$ and $d n d 2$ plants to virulent and avirulent $P$. syringae pv. tomato, and of $d n d l$ plants to virulent $H$. parasitica, was dependent on NPRl and required SA synthesized through the SID2-encoded isochorismate synthase, indicating that SA signaling mediated through NPRI is an important contributor to the enhanced resistance of these mutants. SID2-deficient $d n d 1$ and $d n d 2$ plants still carried higher levels of SA than were found in sid2 single mutants, presumably due to SA production via a second isochorismate synthase or the phenylalanine ammonium lyase (PAL) pathway (Wildermuth et al. 2001). Notably, the constitutive $P R-1$ expression of $d n d 1$ plants was reduced in $d n d 1$ nprl plants but was undetectable in $d n d 1$ sid2. Together with the observation that $d n d 1 \mathrm{nprl}$ and $d n d 2 \mathrm{nprl}$ plants showed activation of the $P R-2$ promoter-GUS construct, this suggests that NPRI-independent, SA-dependent pathways leading to $P R$ gene expression are activated in $d n d l$ and $d n d 2$. Activation of NPRl-independent SA-dependent pathways has been previously observed (Clarke et al. 2000; Greenberg 2000; Nandi et al. 2003; Shah et al. 1999, 2001). We found that resistance to P. syringae pv. tomato and to $H$. parasitica, and constitutive expression of $P R-1$, appear to be dependent specifically on SA produced via SID2,

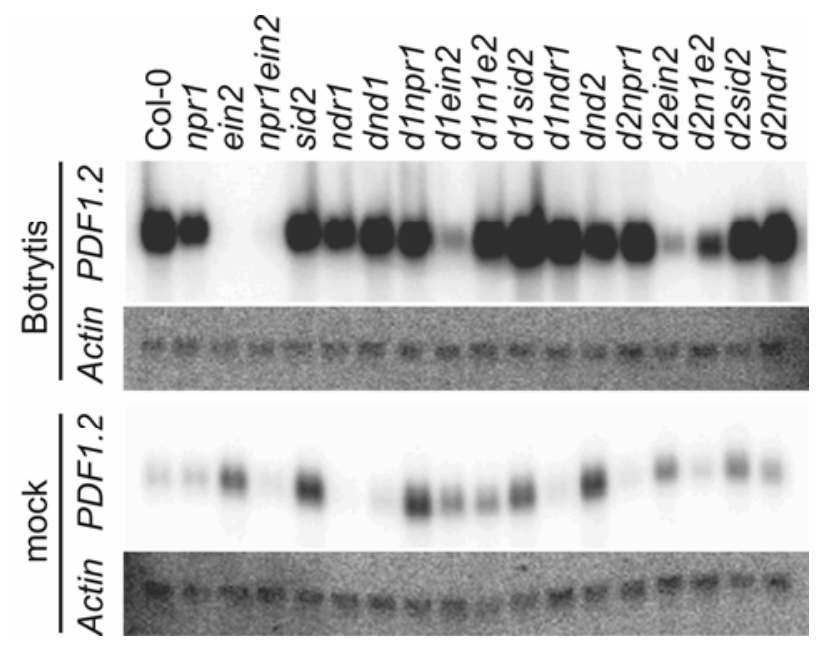

Fig. 9. PDF1.2 expression in $d n d 1$ double mutants inoculated with Botrytis cinerea. Two-month-old plants were inoculated with $B$. cinerea at $2 \times$ $10^{5}$ spores $/ \mathrm{ml}$. Sample order is the same for both blots. Tissue samples were collected from Botrytis cinerea-inoculated or mock-inoculated plants 3 days postinoculation. Actin served as a loading control. Experiment was performed twice with similar results. suggesting that SID2 activity may be required to produce SA in appropriate cellular locations or to sufficient levels for defense activation.

Although NPRl-independent pathways were activated in $d n d 1$ and $d n d 2$ plants, they were not effective in defense against virulent $P$. syringae pv. tomato and $H$. parasitica or avirulent $P$. syringae pv. tomato, because these pathogens were no less successful on $d n d 1$ or $d n d 2$ plants mutated at NPRI or SID2 than on nprl and sid2 single mutants. Interestingly, dndl sid2 and $d n d 2$ sid2 plants supported higher populations of avirulent $P$. syringae pv. tomato than did sid2 plants, and $d n d 1$ sid2 plants were more susceptible to $H$. parasitica than sid2 plants (Figs. 4 and 7; H. W. Jung and J. T. Greenberg, unpublished results).

The dndl mutants show reduced symptom development when inoculated with $P$. syringae. This phenotype was maintained in dnd1 nprl plants but lost in dnd1 sid2 and dndl ndrl plants, suggesting that SA is required for $d n d l$-mediated suppression of symptom development via an NPRl-independent pathway. Because $n d r l$ plants are impaired in SA accumulation after inoculation (Shapiro and Zhang 2001), the observation that $d n d 1 n d r l$ plants show chlorotic symptoms similar to $n d r l$ plants is consistent with a requirement for SA for $d n d 1$ mediated disease symptom suppression.

The dndl nprl and dnd2 nprl mutants showed increased SA levels compared with $d n d l$ and $d n d 2$, presumably due to the loss of feedback regulation of SA accumulation by NPRI (Delaney et al. 1995; Shah et al. 1997; Wildermuth et al. 2001). Similar increases in SA levels due to nprl have been reported for other constitutive defense mutants, including ssi2 (Shah et al. 2001) and the cpr mutants (Clarke et al. 2000). Interestingly, dndl $n p r l$ and $d n d 2 n p r l$ plants responded differently to this increase in SA. Although $d n d 2$ nprl plants showed a slight size increase compared with $d n d 2$ single mutants, dndl nprl plants showed exacerbated dwarfing compared with $d n d 1$, as well as spontaneous lesion formation. NPRl may repress or promote cell death depending on the cellular context: for example, NPRl represses the HR but promotes spontaneous cell death in the lesion mimic mutant agd2 (Rate and Greenberg 2001) and promotes lesion development in the hrll lesion mimic mutant (Devadas et al. 2002). Evidently, NPRI suppresses lesion formation in $d n d 1$ but not $d n d 2$.

Small differences between $d n d 1$ and $d n d 2$ mutants were also observed in experiments with virulent $P$. syringae pv. tomato DC3000, where the nprl mutation entirely disrupted the elevated resistance of $d n d l$ but only partially disrupted $d n d 2$ resistance, and the $n d r l$ mutation partially disrupted the elevated resistance of $d n d 2$ but not $d n d 1$. Although the phenotypic impacts on the plant caused by loss of the DND1/CNGC2 and DND2/CNGC4 ion channels is overall quite similar, these results point to subtle differences in pathways activated in $d n d 1$ as opposed to $d n d 2$ mutants.

Returning to the discussion of plant morphologies, triplemutant studies with $d n d 1$ showed that introduction of ein 2 into the dnd1 nprl mutants prevented the development of spontaneous lesions and restored them to a rosette size similar to $d n d l$, suggesting that ethylene signaling is involved in lesion formation in these plants. Ethylene has previously been implicated as a regulator of ozone-induced lesion formation in Arabidopsis (Rao et al. 2002; Tuominen et al. 2004).

$N D R 1$ is required for resistance mediated by the genes $R P M 1, R P S 2$, and RPS5 (Century et al. 1995); therefore, it was not surprising to see an NDR1 requirement for the enhanced resistance of $d n d 1$ and $d n d 2$ to DC3000 expressing avrRpt2, recognized by $R P S 2$-expressing plants. However, $d n d 2$ also showed a partial requirement for $N D R l$ for resistance to virulent DC3000. Although dndl plants did not show a statistically 
significant $N D R 1$ requirement for resistance to virulent $P$. syringae pv. tomato, mutation of $n d r l$ eliminated $d n d l$ resistance to virulent $H$. parasitica. Evidently, the enhanced resistance of both $d n d l$ and $d n d 2$ to certain virulent pathogens requires $N D R 1$. However, other phenotypes of the $d n d 1$ and $d n d 2 \mathrm{mu}-$ tants, including SA accumulation, dwarfing, and constitutive $P R-1$ expression, showed only a partial $N D R l$ requirement or no requirement for NDR1. This mirrors previous findings for the role of PAD4 in the dnd phenotypes: both $d n d 1$ and $d n d 2$ have previously been shown to require $P A D 4$ for resistance to virulent $P$. syringae, although $d n d 1$ and $d n d 2$ SA levels, constitutive $P R-1$ expression, and rosette size were unaffected by the pad4 mutation (Jirage et al. 2001). The requirement for both $P A D 4$ and NDR1, considered to define separate signaling pathways downstream of distinct groups of $R$ genes (Aarts et al. 1998; Feys et al. 2001), in the enhanced resistance of $d n d l$ and $d n d 2$ to $P$. syringae and $H$. parasitica suggests that these mutants activate multiple defense pathways. However, it is important to note that measurements of SA levels in $d n d 1$ and $d n d 2$ plants impaired in either PAD4 (Jirage et al. 2001) or NDRI (this article) were performed on noninoculated plants. Because both PAD4 and NDRI are involved in accumulation of SA postinoculation (Jirage et al. 1999; Shapiro and Zhang 2001; Zhou et al. 1998), it is also possible that impaired disease resistance in $d n d$ pad4 or $d n d n d r l$ double mutants is simply due to impaired SA accumulation upon infection. If so, this would explain the apparent uncoupling of SA accumulation and $P R-1$ expression from enhanced resistance seen in $d n d l n d r l$ plants.

In other lesion-mimic mutants, similar uncoupling of resistance from phenotypes such as $P R$ gene expression and SA accumulation has been seen (Clarke et al. 1998; Greenberg and Yao 2004; Yoshioka et al. 2006). The cpr22 mutant, which results from a fusion of two cyclic nucleotide-gated ion channel genes (Yoshioka et al. 2006), provides a particularly relevant example. Epistasis analyses indicated that the enhanced resistance of cpr22 to virulent $H$. parasitica and $P$. syringae pathogens required functional NDR1, PAD4, and EDS1 genes, whereas other phenotypes such as stunting, constitutive $P R-1$ expression, spontaneous lesions, and SA accumulation were independent of NDR1, PAD4, and EDS1 (Yoshioka et al. 2006).

None of the defense mutations introduced into $d n d 1$ or $d n d 2$ led to restoration of the HR in response to challenge with avirulent $P$. syringae pv. tomato DC3000. In other mutants that lack the HR, alteration of SA signaling or SAR induction has been shown to restore the HR: the HR was restored in agd2 mutants that lacked a functional NPR1 gene (Rate and Greenberg 2001), and introduction of the nprl mutation, depletion of SA by $n a h G$, or induction of SAR restored the HR in the hrll mutant (Devadas and Raina 2002). As previously mentioned, dndl nprl plants showed spontaneous lesions not seen for $d n d 1$, and these were suppressed by introduction of ein2. However, an $\mathrm{HR}$ in response to inoculation with avirulent pathogen was still absent. Like the HR, normal rosette size was not restored by introduction of any of the defense mutations introduced into $d n d 1$ or $d n d 2$. Slight size increases were seen when sid 2 or $n d r l$ were introduced into $d n d 1$ or $d n d 2$, or $n p r l$ into $d n d 2$. It has previously been shown that expression of the bacterial salicylate hydroxylase gene $n a h G^{+}$in $d n d 1$ and $d n d 2$ only partially relieves the dwarf phenotype, suggesting, as do the results reported here, that other factors beside the level of SA affect rosette size in these mutants (Clough et al. 2000; Jurkowski et al. 2004). These two aspects of the $d n d$ phenotypes, rosette size and lack of HR, are clearly affected by mechanisms or pathways beyond those that were explicitly examined in the present study.

EIN2 is important for defense against $B$. cinerea but is relatively uninvolved in resistance to $P$. syringae pv. tomato
DC3000 and $H$. parasitica, SA accumulation, and $P R-1$ expression (Balbi and Devoto 2008; Pieterse and Van Loon 2004; Thomma et al. 1999). This was also true in ein2 double mutants with $d n d 1$ or $d n d 2$. Previous work has suggested that the enhanced resistance of $d n d l$ to $B$. cinerea is due to its deficient programmed cell death response (Govrin and Levine 2000). Although altered programmed cell death may be a contributing factor to the elevated resistance of $d$ nd mutants to $B$. cinerea, the ethylene pathway is more significant. The dnd1 ein2 and dnd2 ein2 plants still had a deficient HR in response to $P$. syringae pv. tomato, yet were highly susceptible to $B$. cinerea.

The JA or ethylene defense pathways that are induced by wounding, herbivory, and necrotrophic pathogens are often monitored by tracking PDF1.2 expression, and PDF1.2 expression shows EIN2-dependence (Balbi and Devoto 2008; Penninckx et al. 1998; Pieterse and Van Loon 2004; Thomma et al. 1998). In the present study, PDF1.2 was expressed after challenge with $B$. cinerea except in ein 2 , dndl ein 2 and $d n d 2$ ein2 lines, as might be predicted. Interestingly, we observed constitutive expression of PDF1.2 in dnd1 nprl and dnd1 sid2 plants that is absent in $d n d 1$, nprl, or sid2 single mutants. Apparently, the constitutively elevated defense activation in dnd mutants is channeled preferentially toward NPR1- and SA-dependent pathways but is channeled toward PDF1.2-associated pathways when SA-associated pathways are not available. This $P D F 1.2$ overexpression in $d n d 1$ nprl and $d n d 1$ sid2 plants was downregulated after inoculation with virulent or avirulent DC3000. Although cross-talk between JA and SA pathways is partially understood (Balbi and Devoto 2008; Beckers and Spoel 2006; De Vos et al. 2006; Dong 2004; Pieterse and Van Loon 2004; Spoel et al. 2003), the mechanism that directs this defense signaling toward and away from PDF1.2 pathways in plants carrying dnd mutations is not known and could be examined through future study both of host factors and of pathogen effectors.

Possibly related to the preceding matter, RPS2-mediated defense was operational in $d n d$ sid2 double mutants (DC3000 grew less if it expressed avrRpt2) (Fig. 4C and D) but growth of DC3000 expressing avrRpt2 was substantially higher in leaves of $d n d 1$ sid 2 and $d n d 2$ sid 2 than in leaves of $d n d 1$, $d n d 2$, or sid 2 alone. The virulence contribution of AvrRpt 2 may be greater when $d n d$ mutations are present in the sid 2 background, or the redirection of $d n d$-activated defense signaling toward $P D F 1.2$-associated pathways may prevent effective activation of $R$-gene-mediated defenses that can otherwise operate in a sid2 mutant.

Of further interest, dnd1 nprl ein 2 and $d n d 2$ nprl ein 2 triple mutants inoculated with $B$. cinerea showed restoration of resistance and of PDF1.2 expression that was absent in dndl ein2 and $d n d 2$ ein2. Mutation of NPR1 presumably allows activation of EIN2-independent JA or ethylene defense pathways and reduces damage from $B$. cinerea by releasing the suppression of JA or ethylene responses mediated by NPRI (Spoel et al. 2003). Together with the observation that mutation of genes from several different defense pathways impairs the enhanced resistance of $d n d$ mutants, the above findings suggest that the loss of cyclic nucleotide-gated ion channels in $d n d 1$ and $d n d 2$ plants, rather than activating a particular defense pathway, produces a generalized defense activation signal. This is consistent with recent findings (Ali et al. 2007) suggesting that NO may be the or one of the relevant signals. The signal derived from loss of $D N D / C N G C$ ion channels is preferentially transduced through SA-mediated pathways, is directed to JA or ethylene pathways if the SA pathways are disrupted, and can be further redirected if both SA and JA or ethylene pathways are disrupted, or upon pathogen infection. 


\section{MATERIALS AND METHODS}

\section{Growth conditions.}

Unless noted otherwise, all plants were grown in 9-h photoperiods at $22^{\circ} \mathrm{C}$. Light intensity was in the range of 100 to 180 $\mu \mathrm{E}$. Plants were grown on Sunshine Mix no. 1 and irrigated from below with distilled water.

\section{Generation of double and triple mutants.}

Unless specifically noted, plant lines referenced by a lowercase gene symbol were homozygous for the mutant allele. All double and triple mutants described here were created using $d n d 1$ or $d n d 2$ as the pollen-recipient plant. The mutant alleles used were $d n d 1-1$ (Yu et al. 1998), $d n d 2-1$ (Jurkowski et al. 2004), nprl-1 (Cao et al. 1994), ein2-1 (Guzman and Ecker 1990), ndr1-1 (Century et al. 1995), sid2-2 (eds16-1) (Dewdney et al. 2000), and nprl-1 ein2-1 (Clarke et al. 2001). All mutants were generated in the Arabidopsis thaliana Columbia genetic background. The dnd1-1 mutation was confirmed with a dCAPS marker ( $\mathrm{MboI}$ restriction site) using the primer pair 5' TGCAGGCAGTGTTTTGGTTA and 5'-ATGAGATTAAGAG CAAAACCCGA. The $d n d 2-1$ mutation was confirmed with a dCAPS marker (NlaIII restriction site) using the primer pair 5'-TCCAAATGGGTTCGAGCAT and 5'-GCAATCTTGAAC TGAATCC. Mutants carrying the nprl-1 mutation were identified by screening respective $\mathrm{F}_{2}$ populations with a previously described CAPS marker (Cao et al. 1997). Mutant lines containing the ein2- 1 allele were identified by plating $\mathrm{F}_{2}$ seed on half-strength MS plates containing $10 \mu \mathrm{M}$ 1-amino-cyclopropane-1-carboxylic acid (ACC) and allowing the seedlings to germinate in the dark for 3 to 4 days. Seedlings that displayed ethylene insensitivity were transplanted into soil. All dwarf plants exhibiting ethylene insensitivity were subsequently sequenced at the ein2-1 allele. Triple mutants of dnd1 npr1 ein2 and $d n d 2$ nprl ein2 were first selected on half-strength MS plates containing $10 \mu \mathrm{M}$ ACC, sequenced at ein2-1, and then checked for homozygosity at $n p r l-1$ by polymerase chain reaction. The $n d r l-1$ mutation was detected using the primer pair 5'-AATCTACTACGACGATGTCCAC and 5'-GTAACCGATG GCAACTTTCAC. The sid2-2 mutation was detected using the primer pair 5'-TTACGGTAATCGCGGAAGAG and 5'-AAGC TTGCAAGAGTGCAACA.

\section{Plant growth and histochemical GUS assay.}

Plant growth characteristics such as rosette size relative to control genotypes were noted for multiple plants in each of numerous experiments across multiple years; single representative plants are shown in Figure 1. The histochemical GUS assay was performed as described (Cao et al. 1994).

\section{Pathogen assays.}

To determine bacterial growth in leaves, 1-month-old plants were inoculated with DC3000 carrying either avrRpt 2 or the empty pVSP61 vector at $5 \times 10^{4} \mathrm{CFU} / \mathrm{ml}$ by vacuum infiltration. At 3 days postinoculation (dpi), homogenized leaf tissue was dilution-plated on selective media as previously described (Yu et al. 1998). For each experiment, four leaf samples were taken per genotype. Each leaf sample comprised a total of four leaf discs taken from two plants.

For observation of disease symptoms, 2-month-old plants were inoculated with DC3000 carrying either avrRpt 2 or the empty pVSP61 vector at $2 \times 10^{5} \mathrm{CFU} / \mathrm{ml}$ by vacuum infiltration; symptoms were observed $3 \mathrm{dpi}$. HR assays were performed by vacuum-infiltrating 2-month-old plants with $P$. syringae pv. glycinea race 4 carrying either avrRpt 2 or the empty pVSP61 vector at $10^{8} \mathrm{CFU} / \mathrm{ml}$; tissue collapse was scored $24 \mathrm{~h}$ postinoculation using a 0 -to-5 scale in which $0=$ no collapse, $1=$ minor damage to less than $5 \%$ of leaves, $2=$ some watersoaked or collapsed tissue present on 5 to $35 \%$ of leaves, $3=35$ to $75 \%$ of leaves watersoaked or collapsed, $4=$ widespread coalescing areas of collapsed leaf tissue, and $5=$ total collapse of all leaves. Combined average of scores from multiple experiments were summarized for Table 1 as 0 to $1.9=-, 2$ to $2.9= \pm, 3$ to $3.9=+$, and 4 to $5=++$. Additional experiments with DC3000 and the plant lines from this study used spray inoculation of 2 to 3week-old seedlings as per Tornero and Dangl (2001); however, the results were variable (poorly reproducible within our lab and too often failing to reproduce published results from other labs). Therefore, data for those experiments are not reported. $H$. parasitica Emco5 assays were performed as previously described (McDowell et al. 2000). Sporangiophore counts per seedling were grouped into four categories prior to ANOVA tests (Fig. 7). For B. cinerea assays, due to leaf size differences between genotypes, whole-plant phenotype tests (spray inoculation) were chosen over lesion size measurement on detached leaves (droplet inoculation; whole-plant disease phenotypes correlate with detached-leaf phenotypes) (Denby et al. 2004; Govrin and Levine 2000; Mengiste et al. 2003). B. cinerea cultures were grown on potato dextrose agar at room temperature for 7 to 10 days. Spores were scraped from the agar surface and resuspended in potato dextrose broth at $2 \times 10^{5}$ spores $/ \mathrm{ml}$. Two-and-a-halfmonth-old plants were lightly sprayed with the spore suspension; domes were placed over the plants to maintain high humidity, and disease assessments were made $7 \mathrm{dpi}$. The pot label identifying the genotype was obscured until plants had been rated for disease symptoms. Disease rating scale used was $0=$ no detectable lesions; 1 = small rare lesions, no fungal growth visible; 2 = lesions on up to $10 \%$ of leaves, little to no fungal growth visible; $3=$ significant necrosis of leaves $(10$ to $30 \%$ of leaves) and visible fungal growth; $4=$ extensive fungal growth, with death of 30 to $60 \%$ of leaves; $5=$ extensive fungal growth, with death of 60 to $80 \%$ of leaves; and $6=$ fungus overgrew plants and less than $10 \%$ of green leaves remained. Inoculation conditions were optimized to provide a wide spread of scores between the most and least susceptible genotypes.

\section{Northern blot analysis.}

RNA isolation was conducted using either mini-to-midi RNA isolation kits (Invitrogen) or RNeasy kits (Qiagen) following the manufacturer's instructions. Northern blots were probed as previously described (Jurkowski et al. 2004). All RNA blot findings are based on independent biological replicates and, in most cases, were performed three or more times.

\section{Quantification of SA.}

Both free and total (including conjugated) SA were quantified from noninoculated leaf tissue of 4-week-old plants as described (Vanacker et al. 2001). Between 0.2 and $0.5 \mathrm{~g}$ of leaf tissue per sample was utilized. The experiment was performed twice, using entirely independent materials and in two separate years.

\section{ACKNOWLEDGMENTS}

We thank N. Keuler and P. Esker for their substantial contributions to the statistical analyses, I-c. Yu for initial construction of some plant lines, J. Clarke and X. Dong for providing npr1 ein2 seed, M. Wildermuth for providing information on sid2-2 primers, T. Mengiste for providing the $B$. cinerea culture and advice in conducting assays, and J. Bergelson for the use of her high-performance liquid chromatograph for SA measurements. This work was primarily supported by United States Department of Agriculture NRI grant 2001-35319-09888 to A. Bent. Experiments in J. T. Greenberg's laboratory were done with support from National Institute of Health grant R01 GM54292 and National Science Foundation grant IOB0450207. 


\section{LITERATURE CITED}

Aarts, N., Metz, M., Holub, E., Staskawicz, B. J., Daniels, M. J., and Parker, J. E. 1998. Different requirements for EDS1 and NDR1 by disease resistance genes define at least two $R$ gene-mediated signaling pathways in Arabidopsis. Proc. Natl. Acad. Sci. U.S.A. 95:1030610311.

Ali, R., Ma, W., Lemtiri-Chlieh, F., Tsaltas, D., Leng, Q., von Bodman, S., and Berkowitz, G. A. 2007. Death don't have no mercy and neither does calcium: Arabidopsis CYCLIC NUCLEOTIDE GATED CHANNEL2 and innate immunity. Plant Cell 19:1081-1095.

Balague, C., Lin, B., Alcon, C., Flottes, G., Malmstrom, S., Kohler, C., Neuhaus, G., Pelletier, G., Gaymard, F., and Roby, D. 2003. HLM1, an essential signaling component in the hypersensitive response, is a member of the cyclic nucleotide-gated channel ion channel family. Plant Cell 15:365-379.

Balbi, V., and Devoto, A. 2008. Jasmonate signalling network in Arabidopsis thaliana: Crucial regulatory nodes and new physiological scenarios. New Phytol. 177:301-318

Beckers, G. J., and Spoel, S. H. 2006. Fine-tuning plant defence signalling: Salicylate versus jasmonate. Plant Biol. (Stuttg.) 8:1-10.

Bendahmane, A., Kanyuka, K., and Baulcombe, D. C. 1999. The Rx gene from potato controls separate virus resistance and cell death responses. Plant Cell 11:781-791.

Bent, A., Innes, R., Ecker, J., and Staskawicz, B. 1992. Disease development in ethylene-insensitive Arabidopsis thaliana infected with virulent and avirulent Pseudomonas and Xanthomonas pathogens. Mol. PlantMicrobe Interact. 5:372-378.

Bowling, S. A., Clarke, J. D., Liu, Y., Klessig, D. F., and Dong, X. 1997. The cpr5 mutant of Arabidopsis expresses both NPR1-dependent and NPR1-independent resistance. Plant Cell 9:1573-1584.

Cao, H., Bowling, S. A., Gordon, A. S., and Dong, X. 1994. Characterization of an Arabidopsis mutant that is nonresponsive to inducers of systemic acquired resistance. Plant Cell 6:1583-1592.

Cao, H., Glazebrook, J., Clarker, J. D., Volko, S., and Dong, X. 1997. The Arabidopsis NPR1 gene that controls systemic acquired resistance encodes a novel protein containing ankyrin repeats. Cell 88:57-63.

Century, K. S., Holub, E. B., and Staskawicz, B. J. 1995. NDR1, a locus of Arabidopsis thaliana that is required for disease resistance to both a bacterial and a fungal pathogen. Proc. Natl. Acad. Sci. U.S.A. 92:65976601

Clarke, J. D., Liu, Y., Klessig, D. F., and Dong, X. 1998. Uncoupling PR gene expression from NPR1 and bacterial resistance: Characterization of the dominant Arabidopsis cpr6-1 mutant. Plant Cell 10:557-569.

Clarke, J. D., Volko, S. M., Ledford, H., Ausubel, F. M., and Dong, X. 2000. Roles of salicylic acid, jasmonic acid, and ethylene in cprinduced resistance in Arabidopsis. Plant Cell 12:2175-2190.

Clarke, J. D., Aarts, N., Feys, B. J., Dong, X., and Parker, J. E. 2001. Constitutive disease resistance requires EDS1 in the Arabidopsis mutants cpr1 and cpr6 and is partially EDS1-dependent in cpr5. Plant J. 26:409420 .

Clough, S. J., Fengler, K. A., Yu, I.-c., Lippok, B., Smith, R. K., and Bent, A. F. 2000. The Arabidopsis dndl "defense, no death" gene encodes a mutated cyclic nucleotide-gated ion channel. Proc. Natl. Acad. Sci. U.S.A. 97:9323-9328

del Pozo, O., and Lam, E. 1998. Caspases and programmed cell death in the hypersensitive response of plants to pathogens. Curr. Biol. 8:R896.

Delaney, T. P., Friedrich, L., and Ryals, J. A. 1995. Arabidopsis signal transduction mutant defective in chemically and biologically induced disease resistance. Proc. Natl. Acad. Sci. U.S.A. 92:6602-6606.

Denby, K. J., Kumar, P., and Kliebenstein, D. J. 2004. Identification of Botrytis cinerea susceptibility loci in Arabidopsis thaliana. Plant J. 38:473-486

Devadas, S. K., and Raina, R. 2002. Preexisting systemic acquired resistance suppresses hypersensitive response-associated cell death in Arabidopsis hrl1 mutant. Plant Physiol. 128:1234-1244.

Devadas, S. K., Enyedi, A., and Raina, R. 2002. The Arabidopsis hrl1 mutation reveals novel overlapping roles for salicylic acid, jasmonic acid and ethylene signalling in cell death and defence against pathogens. Plant J. 30:467-480.

De Vos, M., Van Zaanen, W., Koornneef, A., Korzelius, J. P., Dicke, M., Van Loon, L. C., and Pieterse, C. M. 2006. Herbivore-induced resistance against microbial pathogens in Arabidopsis. Plant Physiol. 142:352-363.

Dewdney, J., Reuber, T. L., Wildermuth, M. C., Devoto, A., Cui, J., Stutius, L. M., Drummond, E. P., and Ausubel, F. M. 2000. Three unique mutants of Arabidopsis identify eds loci required for limiting growth of a biotrophic fungal pathogen. Plant J. 24:205-218.

Dong, X. 2004. NPR1, all things considered. Curr. Opin. Plant Biol. 7:547-552.
Ellis, C., and Turner, J. G. 2001. The Arabidopsis mutant cev1 has constitutively active jasmonate and ethylene signal pathways and enhanced resistance to pathogens. Plant Cell 13:1025-1033.

Ferrari, S., Plotnikova, J. M., De Lorenzo, G., and Ausubel, F. M. 2003. Arabidopsis local resistance to Botrytis cinerea involves salicylic acid and camalexin and requires EDS4 and PAD4, but not SID2, EDS5 or PAD4. Plant J. 35:193-205.

Feys, B. J., and Parker, J. E. 2000. Interplay of signaling pathways in plant disease resistance. Trends Genet. 16:449-455.

Feys, B. J., Moisan, L. J., Newman, M. A., and Parker, J. E. 2001. Direct interaction between the Arabidopsis disease resistance signaling proteins, EDS1 and PAD4. EMBO (Eur. Mol. Biol. Organ.) J. 20:54005411.

Glazebrook, J. 2005. Contrasting mechanisms of defense against biotrophic and necrotrophic pathogens. Annu. Rev. Phytopathol. 43:205-227.

Glazebrook, J., Rogers, E. E., and Ausubel, F. M. 1996. Isolation of Arabidopsis mutants with enhanced disease susceptibility by direct screening. Genetics 143:973-982.

Govrin, E. M., and Levine, A. 2000. The hypersensitive response facilitates plant infection by the necrotrophic pathogen Botrytis cinerea. Curr. Biol. 10:751-757.

Govrin, E. M., and Levine, A. 2002. Infection of Arabidopsis with a necrotrophic pathogen, Botrytis cinerea, elicits various defense responses but does not induce systemic acquired resistance (SAR). Plant Mol. Biol. 48:267-276.

Greenberg, J. T. 2000. Positive and negative regulation of salicylic aciddependent cell death and pathogen resistance in Arabidopsis 1sd6 and ssi1 mutants. Mol. Plant-Microbe Interact. 13:877-881.

Greenberg, J. T., and Yao, N. 2004. The role and regulation of programmed cell death in plant-pathogen interactions. Cell. Microbiol. 6:201-211.

Guzman, P., and Ecker, J. R. 1990. Exploiting the triple response of Arabidopsis to identify ethylene-related mutants. Plant Cell 2:513-523.

Hammond-Kosack, K. E., and Parker, J. E. 2003. Deciphering plant-pathogen communication: Fresh perspectives for molecular resistance breeding. Curr. Opin. Biotechnol. 14:177-193.

Heath, M. C. 2000. Hypersensitive response-related death. Plant Mol. Biol. 44:321-334.

Hoffman, T., Schmidt, J. S., Zheng, X., and Bent, A. F. 1999. Isolation of ethylene insensitive soybean mutants that are altered in pathogen susceptibility and gene-for-gene disease resistance. Plant Physiol. 119:935949.

Hua, B. G., Mercier, R. W., Leng, Q., and Berkowitz, G. A. 2003. Plants do it differently. A new basis for potassium/sodium selectivity in the pore of an ion channel. Plant Physiol. 132:1353-1361.

Jakobek, J. L., and Lindgren, P. B. 1993. Generalized induction of defense responses in bean is not correlated with the induction of the hypersensitive reaction. Plant Cell 5:49-56.

Jirage, D., Tootle, T. L., Reuber, T. L., Frost, L. N., Feys, B. J., Parker, J. E., Ausubel, F. M., and Glazebrook, J. 1999. Arabidopsis thaliana PAD4 encodes a lipase-like gene that is important for salicylic acid signaling. Proc. Natl. Acad. Sci. U. S. A. 96:13583-13588.

Jirage, D., Zhou, N., Cooper, B., Clarke, J. D., Dong, X., and Glazebrook, J. 2001. Constitutive salicylic acid-dependent signaling in cpr1 and cpr6 mutants requires PAD4. Plant J. 26:395-407.

Jones, J. D., and Dangl, J. L. 2006. The plant immune system. Nature 444:323-329.

Jurkowski, G. I., Smith, R. K., Jr., Yu, I. C., Ham, J. H., Sharma, S. B., Klessig, D. F., Fengler, K. A., and Bent, A. F. 2004. Arabidopsis DND2, a second cyclic nucleotide-gated ion channel gene for which mutation causes the "defense, no death" phenotype. Mol. Plant-Microbe Interact. 17:511-520.

Knoester, M., van Loon, L. C., van den Heuvel, J., Hennig, J., Bol, J. F., and Linthorst, H. J. M. 1998. Ethylene-insensitive tobacco lacks nonhost resistance against soil-borne fungi. Proc. Natl. Acad. Sci. U. S. A. 95:1933-1937.

Knoester, M., Pieterse, C. M., Bol, J. F., and Van Loon, L. C. 1999. Systemic resistance in Arabidopsis induced by rhizobacteria requires ethylene-dependent signaling at the site of application. Mol. Plant-Microbe Interact. 12:720-727.

Kohler, C., and Neuhaus, G. 2000. Characterisation of calmodulin binding to cyclic nucleotide-gated ion channels from Arabidopsis thaliana. FEBS (Fed. Eur. Biochem. Soc.) Lett. 471:133-136.

Kohm, B. A., Goulden, M. G., Gilbert, J. E., Kavanagh, T. A., and Baulcombe, D. C. 1993. A potato virus X resistance gene mediates an induced, nonspecific resistance in protoplasts. Plant Cell 5:913-920.

Leng, Q., Mercier, R. W., Hua, B. G., Fromm, H., and Berkowitz, G. A. 2002. Electrophysiological analysis of cloned cyclic nucleotide-gated ion channels. Plant Physiol. 128:400-410.

Leng, Q., Mercier, R. W., Yao, W., and Berkowitz, G. A. 1999. Cloning 
and first functional characterization of a plant cyclic nucleotide-gated cation channel. Plant Physiol. 121:753-761.

Lorenzo, O., Piqueras, R., Sanchez-Serrano, J. J., and Solano, R. 2003. ETHYLENE RESPONSE FACTOR1 integrates signals from ethylene and jasmonate pathways in plant defense. Plant Cell 15:165-178.

Lucas, J. A. 1998. Plant Pathology and Plant Pathogens. Blackwell Science, Oxford (Malden, MA, U.S.A.).

Lund, S. T., Stall, R. E., and Klee, H. J. 1998. Ethylene regulates the susceptible response to pathogen infection in tomato. Plant Cell 10:371-382.

Maser, P., Thomine, S., Schroeder, J. I., Ward, J. M., Hirschi, K., Sze, H., Talke, I. N., Amtmann, A., Maathuis, F. J., Sanders, D., Harper, J. F., Tchieu, J., Gribskov, M., Persans, M. W., Salt, D. E., Kim, S. A., and Guerinot, M. L. 2001. Phylogenetic relationships within cation transporter families of Arabidopsis. Plant Physiol. 126:1646-1667.

McDowell, J. M., Dhandaydham, M., Long, T. A., Aarts, M. G., Goff, S., Holub, E. B., and Dangl, J. L. 1998. Intragenic recombination and diversifying selection contribute to the evolution of downy mildew resistance at the RPP8 locus of Arabidopsis. Plant Cell 10:1861-1874.

McDowell, J. M., Cuzick, A., Can, C., Beynon, J., Dangl, J. L., and Holub, E. B. 2000. Downy mildew (Peronospora parasitica) resistance genes in Arabidopsis vary in functional requirements for NDR1, EDS1, NPR1 and salicylic acid accumulation. Plant J. 22:523-529.

Mengiste, T., Chen, X., Salmeron, J., and Dietrich, R. 2003. The BOTRYTIS SUSCEPTIBLE1 gene encodes an R2R3MYB transcription factor protein that is required for biotic and abiotic stress responses in $\mathrm{Arabi}$ dopsis. Plant Cell 15:2551-2565.

Nandi, A., Kachroo, P., Fukushige, H., Hildebrand, D. F., Klessig, D. F., and Shah, J. 2003. Ethylene and jasmonic acid signaling affect the NPR1-independent expression of defense genes without impacting resistance to Pseudomonas syringae and Peronospora parasitica in the Arabidopsis ssi1 mutant. Mol. Plant-Microbe Interact. 16:588-599.

Nawrath, C., and Metraux, J. P. 1999. Salicylic acid induction-deficient mutants of Arabidopsis express PR-2 and PR-5 and accumulate high levels of camalexin after pathogen inoculation. Plant Cell 11:13931404.

Nimchuk, Z., Eulgem, T., Holt, B. F., III, and Dangl, J. L. 2003. Recognition and response in the plant immune system. Annu. Rev. Genet. 37:579-609.

Nurnberger, T., and Scheel, D. 2001. Signal transmission in the plant immune response. Trends Plant Sci. 6:372-379.

Overmyer, K., Tuominen, H., Kettunen, R., Betz, C., Langebartels, C., Sandermann, H., Jr., and Kangasjarvi, J. 2000. Ozone-sensitive Arabidopsis rcd1 mutant reveals opposite roles for ethylene and jasmonate signaling pathways in regulating superoxide-dependent cell death. Plant Cell 12:1849-1862.

Overmyer, K., Brosche, M., and Kangasjarvi, J. 2003. Reactive oxygen species and hormonal control of cell death. Trends Plant Sci. 8:335-342.

Penninckx, I. A., Thomma, B. P., Buchala, A., Metraux, J. P., and Broekaert, W. F. 1998. Concomitant activation of jasmonate and ethylene response pathways is required for induction of a plant defensin gene in Arabidopsis. Plant Cell 10:2103-2113.

Pieterse, C. M., and Van Loon, L. C. 2004. NPR1: The spider in the web of induced resistance signaling pathways. Curr. Opin. Plant Biol. 7:456464

Rao, M. V., Lee, H. I., and Davis, K. R. 2002. Ozone-induced ethylene production is dependent on salicylic acid, and both salicylic acid and ethylene act in concert to regulate ozone-induced cell death. Plant J. 32:447-456.

Rate, D. N., and Greenberg, J. T. 2001. The Arabidopsis aberrant growth and death2 mutant shows resistance to Pseudomonas syringae and reveals a role for NPR1 in suppressing hypersensitive cell death. Plant J. 27:203-211.

Rate, D. N., Cuenca, J. V., Bowman, G. R., Guttman, D. S., and Greenberg, J. T. 1999. The gain-of-function Arabidopsis acd6 mutant reveals novel regulation and function of the salicylic acid signaling pathway in controlling cell death, defenses, and cell growth. Plant Cell 11:1695-1708.

Rogers, E. E., and Ausubel, F. M. 1997. Arabidopsis enhanced disease susceptibility mutants exhibit enhanced susceptibility to several bacterial pathogens and alterations in PR-1 gene expression. Plant Cell 9:305-316.

Rojo, E., Leon, J., and Sanchez-Serrano, J. J. 1999. Cross-talk between wound signalling pathways determines local versus systemic gene expression in Arabidopsis thaliana. Plant J. 20:135-142.

Ryals, J. A., Neuenschwander, U. H., Willits, M. G., Molina, A., Steiner, H.-Y., and Hu, M. D. 1996. Systemic acquired resistance. Plant Cell 8:1809-1819.
Shah, J., Tsui, F., and Klessig, D. F. 1997. Characterization of a salicylic acid-insensitive mutant (sai1) of Arabidopsis thaliana, identified in a selective screen utilizing the SA-inducible expression of the tms 2 gene. Mol. Plant-Microbe Interact. 10:69-78.

Shah, J., Kachroo, P., and Klessig, D. F. 1999. The Arabidopsis ssi1 mutation restores pathogenesis-related gene expression in npr1 plants and renders defensin gene expression salicylic acid dependent. Plant Cell 11:191-206.

Shah, J., Kachroo, P., Nandi, A., and Klessig, D. F. 2001. A recessive mutation in the Arabidopsis SSI2 gene confers SA- and NPR1-independent expression of $P R$ genes and resistance against bacterial and oomycete pathogens. Plant J. 25:563-574.

Shapiro, A. D., and Zhang, C. 2001. The role of NDR1 in avirulence genedirected signaling and control of programmed cell death in Arabidopsis. Plant Physiol. 127:1089-1101.

Spoel, S. H., Koornneef, A., Claessens, S. M., Korzelius, J. P., Van Pelt, J. A., Mueller, M. J., Buchala, A. J., Metraux, J. P., Brown, R., Kazan, K. Van Loon, L. C., Dong, X., and Pieterse, C. M. 2003. NPR1 modulates cross-talk between salicylate- and jasmonate-dependent defense pathways through a novel function in the cytosol. Plant Cell 15:760-770.

Staswick, P. E., Yuen, G. Y., and Lehman, C. C. 1998. Jasmonate signaling mutants of Arabidopsis are susceptible to the soil fungus Pythium irregulare. Plant J. 15:747-754.

Tao, Y., Xie, Z., Chen, W., Glazebrook, J., Chang, H. S., Han, B., Zhu, T., Zou, G., and Katagiri, F. 2003. Quantitative nature of Arabidopsis responses during compatible and incompatible interactions with the bacterial pathogen Pseudomonas syringae. Plant Cell 15:317-330.

Thomma, B. P., Eggermont, K., Penninckx, I. A., Mauch-Mani, B., Vogelsang, R., Cammue, B. P., and Broekaert, W. F. 1998. Separate jasmonate-dependent and salicylate-dependent defense-response pathways in Arabidopsis are essential for resistance to distinct microbial pathogens. Proc. Natl. Acad. Sci. U. S. A. 95:15107-15111.

Thomma, B. P., Eggermont, K., Tierens, K. F., and Broekaert, W. F. 1999. Requirement of functional ethylene-insensitive 2 gene for efficient resistance of Arabidopsis to infection by Botrytis cinerea. Plant Physiol. 121:1093-1102

Tornero, P., and Dangl, J. L. 2001. A high-throughput method for quantifying growth of phytopathogenic bacteria in Arabidopsis thaliana. Plant J. 28:475-481.

Tuominen, H., Overmyer, K., Keinanen, M., Kollist, H., and Kangasjarvi, J. 2004. Mutual antagonism of ethylene and jasmonic acid regulates ozone-induced spreading cell death in Arabidopsis. Plant J. 39:59-69.

Urquhart, W., Gunawardena, A. H., Moeder, W., Ali, R., Berkowitz, G. A. and Yoshioka, K. 2007. The chimeric cyclic nucleotide-gated ion channel ATCNGC11/12 constitutively induces programmed cell death in a $\mathrm{Ca} 2+$ dependent manner. Plant Mol. Biol. 65:747-761.

Vanacker, H., Lu, H., Rate, D. N., and Greenberg, J. T. 2001. A role for salicylic acid and NPR1 in regulating cell growth in Arabidopsis. Plant J. 28:209-216.

Volko, S. M., Boller, T., and Ausubel, F. M. 1998. Isolation of new Arabidopsis mutants with enhanced disease susceptibility to Pseudomonas syringae by direct screening. Genetics 149:537-548.

Wildermuth, M. C., Dewdney, J., Wu, G., and Ausubel, F. M. 2001. Isochorismate synthase is required to synthesize salicylic acid for plant defence. Nature 414:562-565.

Yoshioka, K., Kachroo, P., Tsui, F., Sharma, S. B., Shah, J., and Klessig, D. F. 2001. Environmentally sensitive, SA-dependent defense responses in the cpr22 mutant of Arabidopsis. Plant J. 26:447-459.

Yoshioka, K., Moeder, W., Kang, H. G., Kachroo, P., Masmoudi, K. Berkowitz, G., and Klessig, D. F. 2006. The chimeric Arabidopsis CYCLIC NUCLEOTIDE-GATED ION CHANNEL11/12 activates multiple pathogen resistance responses. Plant Cell 18:747-763.

Yu, I.-c., Parker, J., and Bent, A. F. 1998. Gene-for-gene disease resistance without the hypersensitive response in Arabidopsis dnd1 mutant. Proc. Natl. Acad. Sci. U. S. A. 95:7819-7824.

Yu, I.-c., Fengler, K. A., Clough, S. J., and Bent, A. F. 2000. Identification of Arabidopsis mutants exhibiting an altered hypersensitive response in gene-for-gene disease resistance. Mol. Plant-Microbe Interact. 13:277286.

Zhong, H., Lai, J., and Yau, K. W. 2003. Selective heteromeric assembly of cyclic nucleotide-gated channels. Proc. Natl. Acad. Sci. U. S. A. 100:5509-5513.

Zhou, N., Tootle, T. L., Tsui, F., Klessig, D. F., and Glazebrook, J. 1998. PAD4 functions upstream from salicylic acid to control defense responses in Arabidopsis. Plant Cell 10:1021-1030. 